\title{
Naturally Occurring Hydroxytyrosol: Synthesis and Anticancer Potential
}

\author{
R. Bernini*,a ${ }^{*}$ N. Merendino ${ }^{\mathrm{b}}$, A. Romani ${ }^{\mathrm{c}}$ and F. Velotti*,b, \\ ${ }^{a}$ Università degli Studi della Tuscia, Dipartimento di Scienze e Tecnologie per l'Agricoltura, le Foreste, la Natura e l'Energia \\ (DAFNE), Via S. Camillo De Lellis, 01100 Viterbo, Italy; ${ }^{b}$ Università degli Studi della Tuscia, Dipartimento di Scienze Ecologiche e \\ Biologiche (DEB), Largo dell'Università, 01100 Viterbo, Italy; ${ }^{c}$ Dipartimento di Scienze Farmaceutiche, Università degli Studi di \\ Firenze, Via Ugo Schiff 6 - 50019 Sesto Fiorentino (FI), Italy; ${ }^{d}$ Centro Ricerca Sperimentale, Regina Elena Cancer Institute, Via \\ delle Messi d'Oro 156, 00158, Rome, Italy
}

\begin{abstract}
Several epidemiological and animal studies have suggested that polyphenols, a group of secondary plant metabolites occurring mainly in the plant kingdom, may have a protective effect against some chronic degenerative diseases such as cancer. Polyphenols are part of the human diet, being present in vegetal food and beverages. Among them, an olive biophenol named hydroxytyrosol [2-(3,4dihydroxyphenyl)ethanol, HTyr] has recently received particular attention because of its antioxidant, antiproliferative, pro-apoptotic, and anti-inflammatory activities, which have the potential to specifically counteract all cancer hallmarks, thus representing the expectant biological activities underlying the anti-tumor properties of this polyphenol. After a description of the synthetic procedures to prepare pure HTyr, this review takes into consideration the chemopreventive and chemotherapeutic potential of HTyr as the result of its antioxidant, antiproliferative and anti-inflammatory activities. In particular, the review is focused on the current knowledge of the main cellular and molecular mechanisms used by HTyr to affect carcinogenesis, highlighting the specific oncogenic and inflammatory signaling pathways potentially targeted by HTyr.
\end{abstract}

Keywords: Hydroxytyrosol, polyphenols, olive mill, olive oil wastewaters, synthesis, oxidation, proliferation, inflammation, signaling, cancer, carcinogenesis, anti-cancer activity.

\section{INTRODUCTION}

Hydroxytyrosol [2-(3,4-dihydroxyphenyl)ethanol, HTyr] is a natural compound firstly recognized by Stoll et al. as a component of echinacoside, a phenolic glycoside showing antibiotic activity against Staphylococcus aureus extracted from the roots of Echinacea angustifolia [1]. As a matter of fact, echinacoside contains one glucose and two rhamnose moieties, glycosidically linked to one caffeic acid and one dihydroxyphenylethanol residue at the centrally situated rhamnose Fig. (1).

In 1966, Panizzi et al. isolated oleuropein, a bitter glucoside of the olives exhibiting hypotensive activity, and firstly clarified its chemical structure [2]. In the presence of $\beta$-glucosidase, oleuropein was hydrolyzed producing an aglycone and glucose. The chemical structure of the aglycone (HTyr) was demonstrated by the formation of some crystalline derivatives-such as tri( $p$-nitrobenzoate) and dimethyl ether.

Several papers reported the chemical composition of olive fruits (Olea europea L.) and virgin olive oils in terms of polyunsaturated fatty acids and phenolic compounds [3]. These molecules are responsible for the human beneficial properties of virgin olive oil, making it unique from the nutritional point of view. Among biophenols, one of the most interesting is HTyr that has been widely studied demonstrating its numerous biological properties. This small molecule is a potent inhibitor of copper sulfateinduced LDL oxidation and of platelet aggregation (potentially reducing the risk of coronary heart disease and atherosclerosis) [4], acts as antioxidant and metal chelator in animal models [5], scavenges superoxide anion $\left(\mathrm{O}_{2}{ }^{--}\right)$generated by either human polymorphonuclear cells or the xanthine/xanthine oxidase system [6], inhibits proliferation and induces apoptosis in HL-60 leukemia cells [7], prevents DNA damage and tyrosine nitration induced by peroxynitrite [8], protects toward hydrogen-peroxide $\left(\mathrm{H}_{2} \mathrm{O}_{2}\right)$-induced damage in human erythrocytes [9], inhibits passive smoking-induced

*Address correspondence to these authors at the Università degli Studi della Tuscia, Dipartimento di Scienze e Tecnologie per l'Agricoltura, le Foreste, la Natura e l'Energia (DAFNE), Via S. Camillo De Lellis, 01100 Viterbo, Italy; Tel: +39 761 357452; Fax: +39 761 357242; E-mail: berninir@unitus.it; and Università degli Studi della Tuscia, Dipartimento di Scienze Ecologiche e Biologiche (DEB), Largo dell'Università, 01100 Viterbo, Italy; Tel: +39 761 357035; Fax: +39 761 357751; E-mail: velotti@unitus.it.

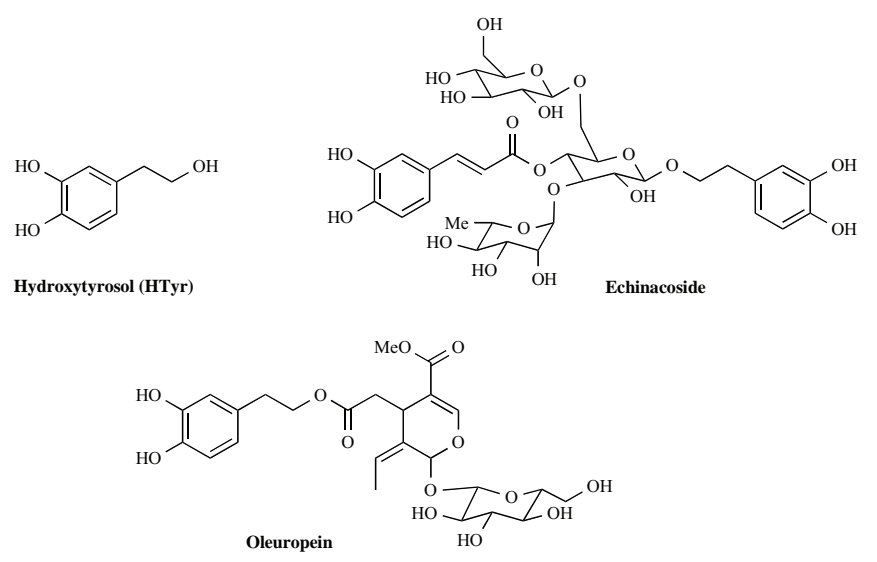

Fig. (1). Chemical structure of hydroxytyrosol (HTyr), echinacoside and oleuropein.

oxidative stress [10], exhibits anti-inflammatory activity [11], exerts anti-microbial and anti-mycoplasmal activity [12].

Considering the health-promoting biological properties of HTyr, many efforts have been made to obtain extracts containing HTyr from natural sources, allowing thus its potential use as a dietary supplement. As a matter of fact, olive pulp extracts were obtained through patented extraction procedures from selected varieties of olives. At the same time, several procedures have been described for the recovery of polyphenols and HTyr from olive oil processing by-products. The definitive production of olive oil is carried out by a three-phase extraction system, which generates liquid and solid wastes. The liquid waste, named olive mill wastewaters (OMWW), contains a mixture of water and oil from the olive vegetal matter, with additional water added from processing. The solid waste is a combination of olive pulp and stones. The use of a more modern two-phases olive oil processing technique, in which no water is added, generates only a byproduct, named alperujo, that is a combination of liquid and solid waste. This system involves a reduction of OMWW volume with an increased concentration in organic matter [13]. Most frequently, OMWW are discharged into evaporation ponds or directly dumped in rivers or spread on soil. These disposals create a number of environmental and ecological problems in all olive-producing countries of the 
Mediterranean region. Olive oil by-products have a high polluting organic load and phenolic compounds are the major contributors to their toxicity and antimicrobial activity [14]. The partition coefficient (oil/water) of most olive biophenols, ranging from $6 \times 10^{-4}$ to 1.5 , is in favor of the water phase. Then, the olive fruits are very rich in phenolic compounds, but only $2 \%$ of the total phenolic content of the olive fruit passes in the oil phase, while the remaining amount is lost in the OMWW and in the pomace (approximately $53 \%$ and $45 \%$, respectively) [15]. On the other hand, phenolic compounds are high value added compounds. Then, procedures for the selective extraction of these compounds allow the detoxification of OMWW and, at the same time, the recovery of biologically active compounds of interest in cosmetic, pharmaceutical and food industries. A recent review described the most recent patents developed to improve procedures for recovering phenolic compounds from olive oil, olive oil industrial by-products and OMWW [16]. Among them, membrane technologies are very efficient for producing purified fractions as powder or concentrated solutions of biologically active phenolic compounds for industrial applications [17]. For example, Olea fractions are obtained from olive oil by-products such as pomace by an innovative process of separation, based on membrane technologies defined as BAT (Best Available Technology) and recognized from EPA (Environmental Protection Agency) $[17 \mathrm{~d}, 17 \mathrm{e}]$. HPLC/DAD/MS analysis of these fractions showed that they contain $90 \%$ of hydroxytyrosol and derivatives. These innovative technologies are recently utilized also for other vegetal matrices such as sweet chestnut (Castanea sativa M.) and artichoke leafs (Cynara), to obtain fractions enriched in hydrolysable tannins [18] and hydroxycinnamic derivatives [19], respectively.

Until some years ago, pure HTyr was commercially available only at a high price (more than 1000 \$ per gram). Currently, HTyr is commercialized by many chemical companies at a lower cost, because in recent times several synthetic procedures have been optimized.

This review article is focused on both the synthetic procedures for HTyr production and the anti-cancer potential of HTyr. In particular, after a survey of HTyr synthesis, the current knowledge of the main cellular and molecular mechanisms used by HTyr to affect carcinogenesis is discussed, highlighting the specific oncogenic and inflammatory signaling pathways potentially targeted by this compound.

\section{SYNTHETIC PROCEDURES}

In 1949, Schöpf et al. claimed the first synthesis of HTyr; a crystalline compound (m.p. $81-83{ }^{\circ} \mathrm{C}$ ) was isolated according to the three-steps procedure described in (Scheme 1) [20]. 2-(3,4-Di methoxyphenyl)ethanol 1 was demethylated by $48 \%$ aqueous hydrobromic acid to produce the corresponding bromide $\mathbf{2}$, that was converted into the triacetoxy derivative $\mathbf{3}$ and then hydrolyzed by methanolic $\mathrm{NH}_{3}$ to give a compound identified as HTyr. Some years ago, in order to evaluate the bacteriostatic action of HTyr on Escherichia coli B., Khafagy and Lambooy prepared a compound by using a new synthetic approach based on the direct demethylation of 2-(3,4-dimethoxyphenyl)ethanol $\mathbf{1}$ by anhydrous $\mathrm{AlCl}_{3}$ in a benzene solution [21]. According to the previously reported value, this compound showed m.p. between 82 and $84{ }^{\circ} \mathrm{C}$ [20].

In 1983, Baraldi et al. repeated the above-described procedures and, although the authors obtained two different compounds showing the previously reported melting points [22], the IR and the ${ }^{1} \mathrm{H}$ NMR data were not consistent with the structure of HTyr; HTyr was only the minor product of the reaction (less than $10 \%$ yield). Then, the same authors synthesized pure HTyr by a new procedure starting from commercially available 3,4-dimethoxyphenylacetic acid 4 (Scheme 2). After a demethylation by hydriodic acid in the presence of red phosphorus, the corresponding dihydroxy derivative 5 was reduced in boiling THF solution with an excess of $\mathrm{LiAlH}_{4}$ to give HTyr in $66 \%$ yield. The physical and spectroscopic data of this compound were consistent with the expected structure of HTyr, as reported by Panizzi et al. [2].

The reduction of 3,4-dihydroxyphenylacetic acid $\mathbf{5}$ using $\mathrm{LiAlH}_{4}$ was optimized in dry THF (obtaining HTyr in $82.8 \%$ yield) by Capasso and co-workers in 1999. After chromatographic purification on a silica gel column, pure HTyr was obtained in $79 \%$ yield and it was fully characterized by ${ }^{1} \mathrm{H}$ NMR, ${ }^{13} \mathrm{C}$ NMR, UV spectroscopy and EIMS spectrometry [23].

One year later, Tuck et al. described the reduction of 3,4dihydroxyphenylacetic acid $\mathbf{5}$ by previously prepared tetrabutylammonium boronate. Under these experimental conditions, HTyr was isolated as pale yellow oil in quantitative yields [24].

Esters have been used as alternative starting materials for the preparation of HTyr. In 1988, Bianco and co-workers described an improved reduction of 3,4-dihydroxyphenethyl acetate 6 using $\mathrm{NaBH}_{4}$ in water (obtaining HTyr in $80 \%$ yield) [25]. The authors supposed that the reaction involved the loss of hydride forming sodium alkoxyborohydrides capable of reducing esters.

Ten years later, 3,4-dihydroxyphenylacetic acid 5 was methylated using $\mathrm{TMSCHN}_{2}$ to produce the corresponding methyl ester 7, which was reduced by $\mathrm{NaBH}_{4}$ in ice water affording to HTyr in 98\% yield (Scheme 4) [26].

Other starting materials for the synthesis of HTyr included tyrosol 8, homovanillyl alcohol 9, 3,4-dimethoxybenzaldehyde $\mathbf{1 0}$ and its demethylated derivative 11, oleuropein $\mathbf{1 2}$.

Both enzymatic and chemical procedures have been optimized for the oxidative conversion of commercially available tyrosol $\mathbf{8}$ into HTyr. Tyrosinase (EC 1.14.18.1) is a polyphenol oxidase exhibiting both monophenolase and diphenolase activity. Firstly, it catalyzes the hydroxylation of monophenols to $o$-phenols and then

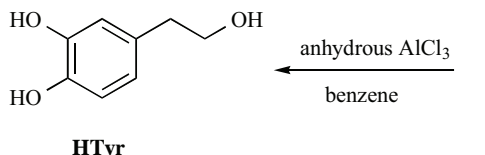

HTyr<smiles>COc1ccc(CCO)cc1OC</smiles>

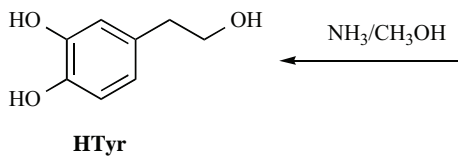

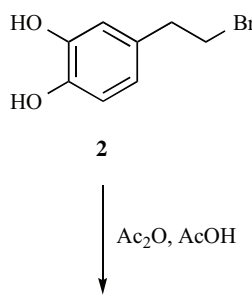

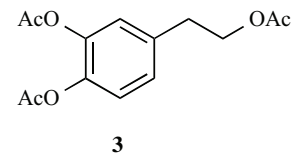

Scheme 1. Synthesis of HTyr proposed by Schöpf et al. [20]. 

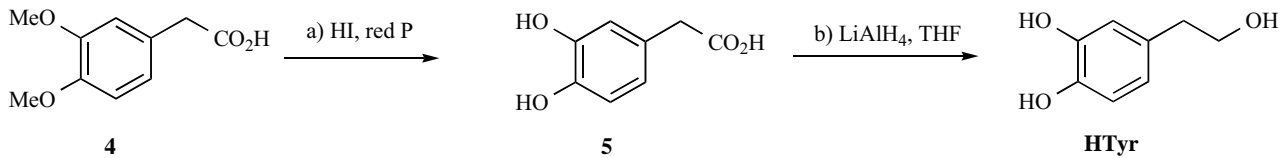

Scheme 2. Synthesis of HTyr reported by Baraldi et al. [22].

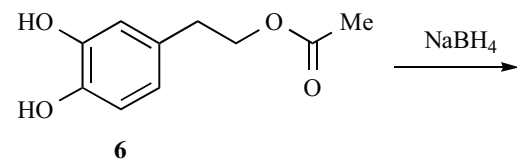<smiles>OCCc1ccc(O)c(O)c1</smiles>

Scheme 3. Reduction of 3,4-dihydroxyphenethyl acetate 6 by $\mathrm{NaBH}_{4}$ [25].
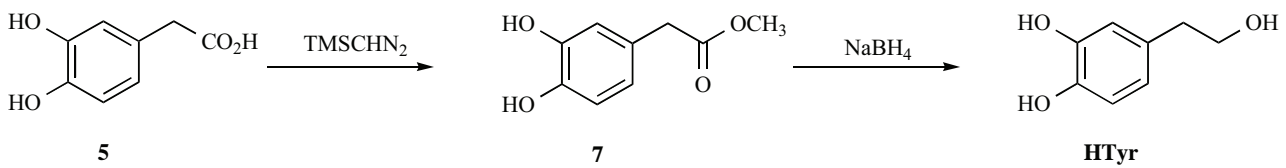

Scheme 4. Preparation and reduction of methyl ester of 3,4-dihydroxyphenylacetic acid 5.

the oxidation of $o$-phenols to the corresponding $o$-quinones. These compounds are very reactive and produced non-enzymatically brown pigments. However, under reducing conditions, $O$-quinones are reduced to the $o$-diphenol precursors. This strategy was used by Espin et al. for the synthesis of HTyr (Scheme 5) [27]. Mushroom tyrosinase was used in the presence of excessive ascorbic acid; the reaction occurred in an aqueous medium, at neutral $\mathrm{pH}$, at room temperature. Once the desired concentration of HTyr was obtained, it was filtered; the enzyme was retained in the filter and reused again. Using a similar strategy, HTyr was synthesized from tyrosol using Agaricus bisporous tyrosinase immobilized on commercial available epoxy-resin Eupergit ${ }^{\circledR} \mathrm{C} 250 \mathrm{~L}$ and coated by the Layerby-Layer method (LbL) [28].

A convenient bioconversion of tyrosol 8 into HTyr was successfully performed using a soil bacterium, Serratia marcescens strain, under environmental friendly conditions [29]. As an alternative, a whole cell system, such as Pseudomonas aeruginosa immobilized resting cells in calcium alginate beads, converted tyrosol $\mathbf{8}$ into HTyr in $86 \%$ yield. The use of immobilized cells in repeated batches demonstrated noteworthy activity stabilization, since the biocatalyst was reused for at least four batches with loss of efficiency [30].

2-Iodoxybenzoic acid (IBX) [31], its stabilized (non explosive) formulation (SIBX) [32] and polymer-supported version such as IBX-polystyrene [33] Fig. (2) are reagents that mimic the monophenolase activity of tyrosinase to produce $o$-quinones from phe- nols. The following in situ reduction produced the corresponding catecholic derivatives. A wide number of examples of $o$ hydroxylation of phenolic compounds and oxidative demethylation of 2-methoxyphenols for the synthesis of biologically and industrially relevant catechols are described in a recent review [34]. Specifically, the (S)IBX-mediated oxidation of tyrosol $\mathbf{8}$ and homovanillyl alcohol 9 followed by an in situ sodium dithionite reduction produced HTyr in modest yields $[35,36]$ (Scheme 7, Table 1, entries 1,3). The efficiency and eco-friendly character of IBXpolystyrene (Table 1, entries 2,4) to give HTyr are noteworthy. As a matter of fact, at the end of the reaction, the solution containing HTyr was filtered; IBX-polystyrene was recovered, regenerated and reused for at least ten subsequent runs. No side-chain oxidation product was observed, demonstrating that recycled IBX-polystyrene fully conserved its high regio- and chemo-selectivity [37].

Alternatively, HTyr was prepared from tyrosol 8 and homovanillyl alcohol 9 using IBX by an indirect route [38]. Firstly, the protection of the primary alcohol function of compounds $\mathbf{8}$ and $\mathbf{9}$ was performed using dimethyl carbonate (DMC), an ecofriendly chemical, in the presence of 1,8-diazabicyclo[5.4.0]undec-7-ene (DBU) or sulfuric acid as catalyst. This allowed to obtain the corresponding methyl carbonates $\mathbf{1 3}$ and $\mathbf{1 4}$ in quantitative yields. Their subsequent IBX-oxidation and reduction furnished hydroxytyrosol methyl carbonate 15 in $85 \%$ yield. Finally, the basic hydrolysis gave HTyr in quasi-quantitative yields (Scheme 7). Compound 15
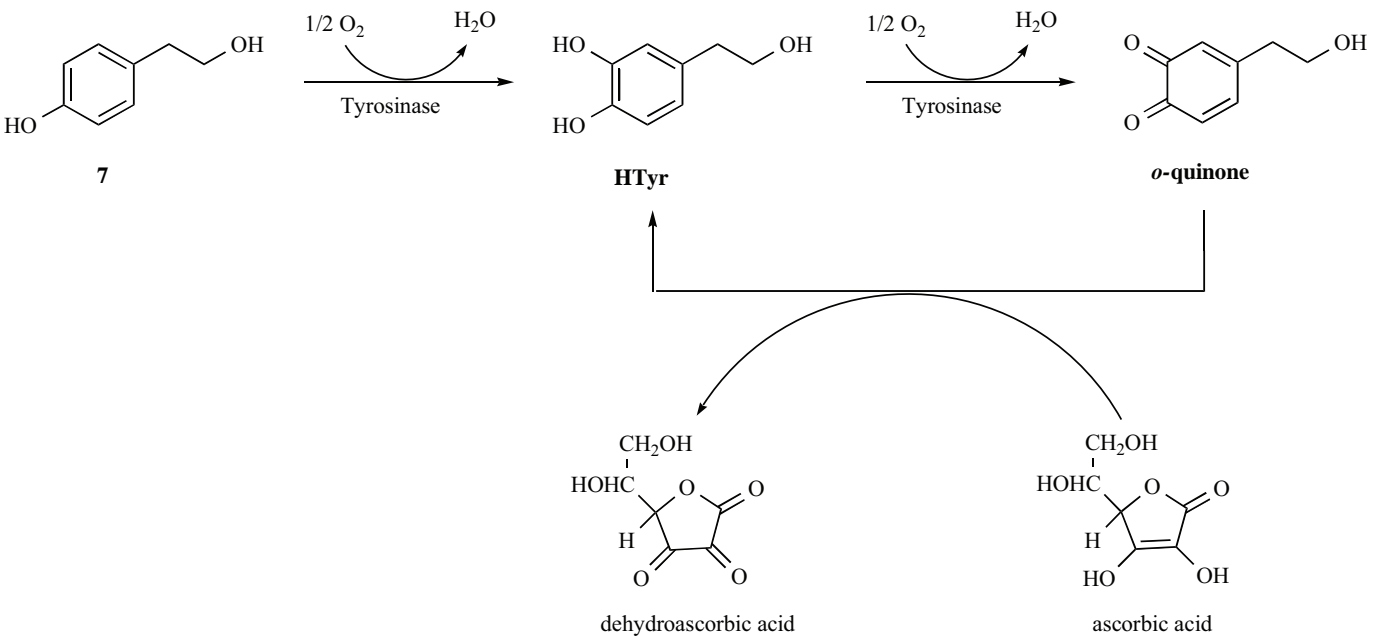

Scheme 5. Synthesis of HTyr from tyrosol 7, in the presence of both mushroom tyrosinase and ascorbic acid. 
<smiles>O=C1OI(=O)(O)c2ccccc21</smiles>

IBX<smiles></smiles><smiles>O=C1OI(=O)(O)c2cc(OCc3ccccc3)ccc21</smiles>

IBX-polystyrene

Fig. (2). IBX-reagents.

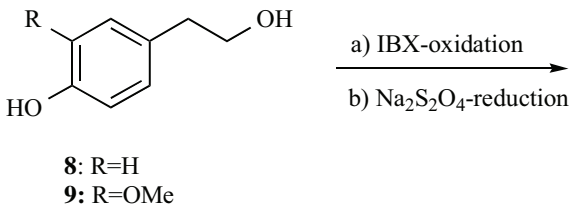<smiles>OCCc1ccc(O)c(O)c1</smiles>

8: $\mathrm{R}=\mathrm{H}$

Scheme 6. Oxidative conversion of tyrosol 8 and homovanillyl alcohol 9 into HTyr.

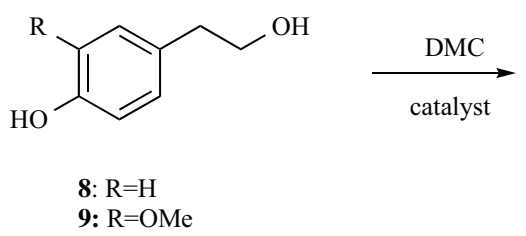<smiles>[R]c1cc(CCOC(=O)OC)ccc1O</smiles>

13: $\mathrm{R}=\mathrm{H}$

9: $\mathrm{R}=\mathrm{OMe}$

14: $\mathrm{R}=\mathrm{OMe}$

IBX-oxidation $\mathrm{Na}_{2} \mathrm{~S}_{2} \mathrm{O}_{4}$-reduction<smiles>OCCc1ccc(O)c(O)c1</smiles><smiles>N#CC(=O)O</smiles><smiles>COC(=O)OCCc1ccc(O)c(O)c1</smiles>

15

Scheme 7. Indirect synthesis of HTyr via IBX-oxidation [38].

Table 1. IBX-Mediated Oxidation of Tyrosol 8 and Homovanillyl Alcohol 9

\begin{tabular}{|l|l|l|l|}
\hline Entry & Starting Material & Experimental Conditions & ${\text { HTyr }(\%)^{\mathbf{a}}}^{\mathbf{a}}$ \\
\hline \hline 1 & Tyrosol 8 & IBX, $\mathrm{CH}_{3} \mathrm{OH},-25^{\circ} \mathrm{C}$ & 30 \\
2 & Tyrosol 8 & IBX-polystyrene, DMC, rt & $>98$ \\
\hline 3 & Homovanillyl alcohol 9 & SIBX, acetone $/ \mathrm{H}_{2} \mathrm{O}=9 / 1, \mathrm{rt}$ & 42 \\
4 & Homovanillyl alcohol 9 & IBX-polystyrene, DMC, $\mathrm{rt}$ & 93 \\
\hline
\end{tabular}

${ }^{a}$ After chromatographic purification.

was proven to be an excellent starting material for the synthesis of a large panel of novel HTyr derivatives [39].

A mild photochemical synthesis of HTyr from tyrosol 8 was described by Azabou et al. [40]. Tyrosol was converted into HTyr (in $64 \%$ yield) by hydrogen peroxide oxidation, using aluminum-iron pillared clay [(Al-Fe)PILC] catalyst under UV irradiation, at $\lambda=254$ $\mathrm{nm}$, at room temperature.

Recently, Bovicelli et al. described an expedient synthesis of HTyr from tyrosol 8, but several steps involving monobromination, substitution, diacetylation and deprotections were necessary to give HTyr in a low overall yield [41].
More recently, Zappia et al. reported an efficient and economical synthesis of HTyr from tyrosol 8 via Baeyer-Villiger oxidation (Scheme 9) [42]. The synthesis began with the protection of tyrosol $\mathbf{8}$ to give the acetate $\mathbf{2 0}$ in quantitative yield; the $o$-formylation furnished the corresponding salicylaldehyde $\mathbf{2 1}$ in $72 \%$ yield. This compound was then subjected to a Bayer-Villiger oxidation to generate the catechol moiety. The subsequent hydrolysis gave HTyr in $79 \%$ yield.

3,4-Dihydroxybenzaldeyde $\mathbf{1 1}$ was used as starting material for the production of HTyr by Verhe et al. [43]. Compound 11 was converted into the corresponding cyanohydrine $\mathbf{2 3}$ and then hydrolyzed to 3,4-dimethoxyphenyl acetic acid 24. The corresponding 
<smiles></smiles><smiles>OCCc1ccc(O)c(O)c1</smiles><smiles>OCCc1ccc(O)c(Br)c1</smiles>

16<smiles>COc1cc(CCO)ccc1O</smiles>

17 $\mathrm{Ac}_{2} \mathrm{O}, \mathrm{AcOH}$<smiles>COc1cc(CCOC(C)=O)ccc1O</smiles>

19<smiles>COc1ccc(CCOC(C)=O)cc1OC</smiles>

18

Scheme 8. Synthesis of HTyr by Bovicelli et al. [41].<smiles>OCCc1ccc(O)cc1</smiles>

8

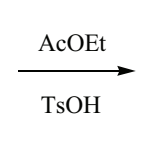

$\mathrm{HO}$<smiles>OCCc1ccc(O)cc1</smiles>

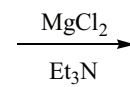<smiles>OCCc1ccc(O)c(O)c1</smiles><smiles>CCOCCc1ccc(O)c(C=O)c1</smiles>

$\mathrm{MCPBA}$

$\checkmark$

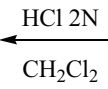<smiles>CC(=O)OCCc1ccc(O)c(O)c1</smiles>

22

Scheme 9. Synthesis of HTyr via Baeyer-Villiger oxidation [42].

methyl ester $\mathbf{2 5}$ was demethylated affording to catecholic ester $\mathbf{2 6}$ and finally reduced to HTyr (Scheme 10).

More recently, commercially available 3,4-dihydroxybenzal dehyde 12 was used as starting material by Zhang et al. [44]. The two free hydroxyl groups of compound $\mathbf{1 2}$ were firstly protected by the benzyl group. Subsequently, one carbon homologation of the protected aldehyde was achieved via the $\alpha$-cyanoenamine $\mathbf{2 8}$, then converted to the carboxylic acid $\mathbf{2 9}$ under acidic conditions. Using $\mathrm{NaBH}_{4}$, compound 29 was reduced into the corresponding alcohol. HTyr was finally obtained by hydrogenolysis under $\mathrm{Pd}-\mathrm{C} / \mathrm{H}_{2}$ conditions (Scheme 11).

As reported above, HTyr was obtained by hydrolysis of oleuropein [2]. Gambacorta et al. described an original procedure, based on the preventive protection of the catecholic moiety of oleuropein into the corresponding acetonide $\mathbf{3 1}$ to protect the molecule against oxidation, thereby allowing long-term storage. The subsequent alkaline hydrolysis of this derivative and deprotection of the acetonide group furnished HTyr in a satisfactory yield (Scheme 12) [45].

Briante et al. reported an efficient enzymatic hydrolysis of oleuropein to give HTyr, by using homogeneous recombinant $\beta$ glycosidase from the hyperthermophilic archeon Sulfolobus solfataricus expressed in Escherichia Coli (EcSßgly) immobilized on a chitosan support [46].

\section{HYDROXYTYROSOL AND CANCER}

As mentioned above, HTyr is one of the major active phenolic compounds in virgin olive oils [3]. Epidemiological studies showed an inverse correlation between olive oil phenol dietary consumption and cancer incidence and number, notably colorectal, breast and prostate cancers [47-49]. Animal studies also demonstrated protection by olive oil phenols towards chemical-induced carcinogenesis, UV-induced skin cancer and spontaneous liver tumors. Other animal studies reported that oleuropein provokes tumor regression [4850]. Therefore, epidemiological and experimental evidence suggest a possible role of olive oil phenols like HTyr in the prevention and the treatment of cancer.

In an important position of a paper published in January 2000, Hanahan and Weinberg listed the following six hallmarks of cancer; as essential requisites for tumorigenesis: sustained proliferative signaling, insensitivity to antigrowth signals, limitless replicative potential, evasion of apoptosis, sustained angiogenesis, and tissue invasion and metastasization [51]. Moreover, although for a long time tumors have been considered as insular masses of proliferating cancer cells, in the last decade since the publication of the paper, it has become increasingly clear that tumors are complex tissues composed of multiple distinct cell types, including transformed and non-transformed cells. The non-transformed tumor-associated component creates the "tumor microenvironment", which contributes to the acquisition of hallmark traits of tumorigenesis. "Tumor microenvironment" includes infiltrating immune cells, some of which, as some inflammatory cells of the innate immunity, serve to promote tumor development. Therefore today, immune inflammatory cells and inflammation have been added as the $7^{\text {th }}$ cancer hallmark [52].

Several studies demonstrated that HTyr is a potent antioxidant phenol and also possesses antiproliferative, pro-apoptotic, as well as anti-inflammatory activities [47-50,53]. These activities have the potential to specific counteract cancer hallmarks, representing thus the expectant biological activities underlying the anti-tumor 
<smiles>COc1ccc(C=O)cc1OC</smiles>

11
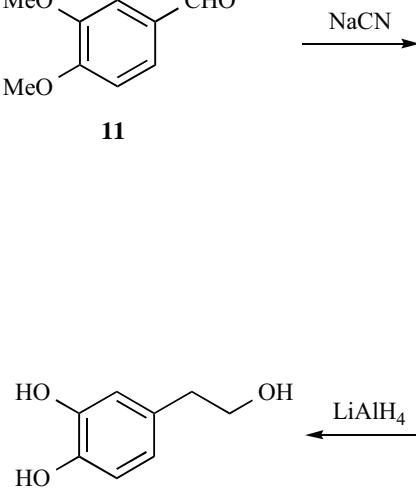

HTyr<smiles>COc1ccc(C(O)C#N)cc1OC</smiles>

23

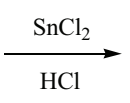

$\mathrm{HCl}$<smiles>COc1ccc(CC(=O)O)cc1OC</smiles>

24

$\mathrm{MeOH}$

$\mathrm{H}_{2} \mathrm{SO}_{4}$<smiles>COc1ccc(CC(C)=O)cc1OC</smiles>

26<smiles>COc1ccc(CC(C)=O)cc1OC</smiles>

25

Scheme 10. Synthesis of HTyr by Verhe et al. [43].

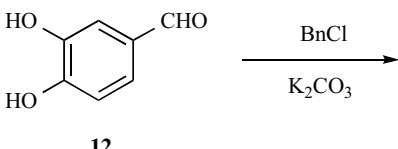

12

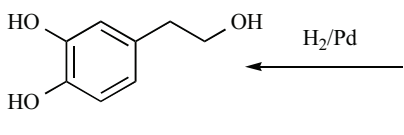

HTyr<smiles>O=Cc1ccc(OCc2ccccc2)c(OCc2ccccc2)c1</smiles>

23

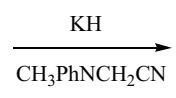<smiles>OCCc1ccc(O)c(O)c1</smiles>

26<smiles>CC(/C(C#N)=C/c1ccc(OCc2ccccc2)c(OCc2ccccc2)c1)c1ccccc1</smiles>

24

Scheme 11. Synthesis of HTyr by Zhang et al. [44].<smiles>CC=C1C(OCC)OC=C(C(C)=O)C1CC(=O)OCCc1ccc(O)c(O)c1</smiles>

Oleuropein<smiles>C/C=C1\C(OC(C)(C)C)OC=C(C(C)=O)C1CC(=O)OCCc1ccc2c(c1)OC(C)(C)O2</smiles>

31<smiles>O=C(O)Cc1ccc(OCc2ccccc2)c(OCc2ccccc2)c1</smiles>

25<smiles>OCCc1ccc(O)c(O)c1</smiles>

HTyr

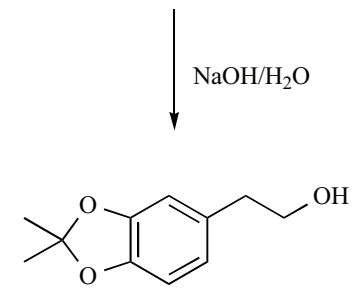

32

Scheme 12. Production of HTyr from oleuropein by Gambacorta et al. [45].

properties of HTyr. The cellular and molecular mechanisms underlying these HTyr-mediated biological activities are not completely clear. Indeed, because of the potential chemopreventive and chemotherapeutic properties of HTyr, investigations devoted to the elucidation of HTyr mode and mechanisms of action have gained recently increasing interest in cancer research. Another unclear point is represented by the reachable plasma concentrations of HTyr following HTyr administration. The large difference in plasma HTyr concentrations reported in the literature is mostly correlated to the difference in the bioavailability of HTyr [54-56]. The administration of HTyr as olive oil ingestion, that is HTyr associated with lipids and other polyphenols, lead to the absorption of approximately $44 \%$ of the total HTyr amount [55]. In contrast, the administration of HTyr as a purified compound in aqueous solution gave 
approximately $10 \%$ of HTyr absorption [56]. Taking into account these considerations, some authors have suggested that physiological HTyr concentrations in the plasma could be between 10 and 100 $\mu \mathrm{M}[57]$.

This part of the review converses the studies involving cellular and molecular mechanisms used by HTyr to affect carcinogenesis, and highlights the specific signaling pathways potentially targeted by HTyr. The knowledge of the molecules directly targeted by HTyr relative to both the experimental cell system (normal $v s$ tumor cells) and the range of HTyr concentrations is essential for a rational use of this compound in cancer prevention and treatment.

\section{OXIDATION AND CANCER}

As a consequence of aerobic metabolism, aerobic organisms produce a wide range of oxygen radicals and other reactive oxygen species (ROS), including free radicals (e.g. $\mathrm{O}_{2}{ }^{--}$and hydroxyl radical $\mathrm{OH}^{-}$) and non-radical compounds (e.g. $\mathrm{H}_{2} \mathrm{O}_{2}$ ). ROS are particularly transient species due to their high chemical reactivity, and, because oxidants by nature, they influence the redox intra- and extra-cellular status.

ROS can be generated from both endogenous and exogenous sources. Intracellular ROS can be generated by various enzyme systems, including the mitochondrial electron transport chain, cytochrome $\mathrm{P} 450$ in the endoplasmic reticulum, lipoxygenase, cyclooxygenase (COX), the NADPH oxidase complex, xanthine oxidase and peroxisomes [58]. Endogenous ROS can derive from innate immune cells (e.g. neutrophils, eosinophils and macrophages) activated by pathogens and/or host factors. Extracellular ROS are frequently a consequence of modifications of plasma membrane proteins and extracellular environment. The principal exogenous sources of ROS are those resulting from exposure to environmental agents, including radiations, xenobiotics, barbiturates, and metal (redox and non-redox) ions [59,60]. ROS production is controlled by both endogenous enzymatic antioxidant systems like superoxide dismutases ( $\mathrm{Cu} / \mathrm{ZnSOD}, \mathrm{MnSOD})$, glutathione (GSH) peroxidase and catalase, and non-enzymatic antioxidants like GSH [60]. Furthermore, exogenous compounds mainly arising from foods, like vitamins $\mathrm{C}$ and $\mathrm{E}$, carotenoids, and polyphenols, also are essential for protection from oxidation.

A persistent imbalance between antioxidants and pro-oxidants in favor of the latter results in excessive ROS levels, which lead to oxidative stress. Elevated oxidative stress is observed in many solid tumors and carcinoma cell lines. Indeed, ROS, reacting with all types of cell molecules, including nucleic acids, proteins, lipids, carbohydrates and small metabolites, can cause both genotoxic and non-genotoxic damages as well as the modulation of numerous cell signaling cascades, including those associated to cell proliferation, cell death, senescence and inflammatory responses. Generally, low oxidative stress may lead to an increased rate of genetic mutations and signaling pathways promoting cell proliferation and survival, whereas higher oxidative stress levels are more likely to cause tumor cell death and/or senescence [61]. Therefore, ROS play a dual role towards tumors, being either beneficial or harmful respectively [62]. In particular, ROS-mediated pro-tumorigenic function consists in the induction of nondestructive oxidative damage in nontransformed and transformed cells, as well as the promotion of metastasis $[63,65]$. Thus, ROS can play a pivotal role in the initiation and the promotion/progression of carcinogenesis [65-67]. Moreover, oxidative stress plays an essential role in the induction of both pro-tumorigenic inflammatory responses and oxidative damage to anti-tumor immune cells, further promoting carcinogenesis (see 6. Inflammation and cancer).

ROS-mediated genotoxic damage mostly involves direct changes in genomic DNA ultimately lead to gene mutations, while non-genotoxic damage includes modulation of gene expression and signaling cascades. Both events, occurring in critical cellular processes, lead to tumor development.

Concerning ROS-mediated genotoxicity, it is known that DNA is a particularly important oxidation target. Indeed, ROS can directly react with DNA molecules, causing strand breaks and pyrimidine and purine lesions, which can affect the integrity of the genome and induce permanent genetic alterations [67]. In addition, ROS can indirectly cause DNA damage. For example, $\mathrm{H}_{2} \mathrm{O}_{2}$ and $\mathrm{O}_{2}{ }^{--}$may initiate DNA damage by interacting with transition metal ion chelates, leading to $\mathrm{OH}$ production. In some cases, the generation of free radicals is closely linked to the involvement of redoxactive metals as iron, and, under stress conditions, $\mathrm{O}_{2}{ }^{-}$excess causes free iron release from iron-containing molecules leading to the generation, through the "Fenton reaction", of highly reactive 'OH' [60]. This radical is perhaps the most frequent DNA damaging species, with over twenty different products derived from its attack to DNA bases. Elevated levels of such DNA lesions can induce aberrant modifications in adjacent DNA, significantly contributing to the genetic instability strongly implicated in all stages of carcinogenesis. Moreover, surmounting evidence implicates the involvement of mitochondrial oxidative DNA damage in human carcinogenesis, being mitochondrial DNA more susceptible to oxidative damage than nuclear DNA [68].

ROS-mediated non-genotoxic damage involves epigenetic alterations that can play a key role in carcinogenesis. In fact, ROS production can cause alterations in DNA methylation (hypo- or hyper- methylation) patterns, altering gene expression [69-71]. For instance, ROS-mediated aberrant hyper-methylation can contribute to gene silencing, leading in certain cases, towards the progression to a malignant phenotype. This is the case of $\mathrm{H}_{2} \mathrm{O}_{2}$ in hepatocellular carcinoma, which induces hyper-methylation of the E-cadherin gene promoter, causing E-cadherin down-regulation, thereby contributing to epithelial-mesenchymal transition and promoting metastasis [72]. ROS can also alter protein structure and function in several ways, by the modification of critical amino acid residues within the functional domain of proteins. By far, the best description of such modifications involves cysteine residues. The sulfhydryl group of a single cysteine residue can be oxidized to form sulfenic, sulfinic, sulfonic, or S-glutathionylated derivatives. Such alterations may alter both the enzyme activity (if the critical cysteine is located within the catalytic domain) and the transcription factor-DNA binding activity (if the cysteine is located within the DNA binding motif), contributing to the non-genotoxic development of carcinogenesis [73]. Therefore, by altering protein structure and function, ROS can act as secondary messengers in cell signaling cascades, affecting the activation or the expression of transcription factors and upstream kinases. For example, $\mathrm{OH}$ and $\mathrm{H}_{2} \mathrm{O}_{2}$ can stimulate proliferation and survival in a wide variety of cell types, by deregulating the function of enzymes involved in the mitogen activated protein kinase (MAPK)- and phosphatidylinositol-3-OH kinase (PI3K)- dependent signaling pathways [74] (see 5. Proliferation and cancer). Then, these signaling cascades, leading to the activation of several redox-regulated transcription factors (e.g. activation protein-AP-1-, nuclear factor-kappa B-NF-kB- and hypoxiainducible factor-1-HIF-1-), up-regulate the expression of antiapoptotic and cell cycle genes, thereby ensuring cell survival and proliferation [74].

In conclusion, oxidative stress can cause oxidative cell damage, initiating and/or maintaining a tumorigenic cell phenotype. However, the "two-faced" functions of ROS must be taken into account, in that, by causing nondestructive or destructive oxidative cell damage, ROS can act as pro-tumorigenic or as anti-tumorigenic chemical species, respectively.

\subsection{HTyr-Mediated Antioxidant Activity and Cancer}

HTyr is a well-established potent antioxidant, probably due to its orthodiphenolic structure and the high electron donating effect of 
the second hydroxyl group [75]. Indeed, HTyr can protect cells from oxidative stress through two types of mechanisms: a direct antioxidant activity (with redox activity) and an indirect antioxidant activity (with or without redox activity). The data concerning these activities are reported in the paragraphs below.

Several studies have shown that HTyr prevents ROS generation in normal and tumor cells, suggesting that it can also prevent oxidative damage in both cell types, thereby preventing both initiation and promotion/progression of tumorigenesis. However, antioxidant effects occurring in an installed malignant disease, where the oxidative status is altered, should be interpreted carefully. Indeed, the reduction of HTyr-mediated oxidative cell damage can cause both anti-tumorigenic (prevention of genetic mutation and proliferation signaling pathways) as well as pro-tumorigenic (promotion of proliferation and/or inhibiting cell death) effects. In the latter case, HTyr might also inhibit the action of those chemotherapeutic agents that induce tumor cell death through oxidative cell damage [76].

In contrast to the described antioxidant activity, in certain cases HTyr behaves as a "pro-oxidant" agent. In fact, depending on HTyr concentrations and cell culture media, HTyr can generate $\mathrm{H}_{2} \mathrm{O}_{2}$ in vitro $[50,54]$. It was indicated that the main initiation step in the $\mathrm{H}_{2} \mathrm{O}_{2}$-producing activity is the auto-oxidation of HTyr by $\mathrm{O}_{2}$, leading to the formation of semiquinone $\mathrm{O}_{2}{ }^{-}$and $2 \mathrm{H}^{+}$[54].

\subsubsection{Direct Antioxidant Activity of HTyr and Cancer}

The direct antioxidant activity of HTyr was demonstrated in vitro and in vivo.

O'Dowd et al. [77] showed that HTyr (10-100 $\mu \mathrm{M})$ possessed a clear scavenging activity in human activated neutrophils in vitroand indicated that this effect was exerted by scavenging $\mathrm{H}_{2} \mathrm{O}_{2}$ but not $\mathrm{O}_{2}{ }^{-}$. Another in vitro study [78] showed that HTyr $(50-100 \mu \mathrm{M})$ reduced hemolysis and membrane lipoperoxidation of $\mathrm{H}_{2} \mathrm{O}_{2}$ pretreated human erythrocytes. The authors also reported that both methionine and leucine membranes transport were significantly reduced after $\mathrm{H}_{2} \mathrm{O}_{2}$ stimulation, suggesting that this could be one of the mechanisms underlying the protective role of HTyr on erythrocyte hemolysis. Furthermore, Fabiani et al. [79] showed that HTyr $(1-10 \mu \mathrm{M})$ prevented oxidative DNA damage in human normal blood mononuclear cells, and suggested that HTyr might efficiently prevent the initiation step of carcinogenesis in vivo, since the concentrations HTyr used could be easily reached with normal olive oil intake. It has been also shown [80] that HTyr $(6.25-100 \mu \mathrm{M})$ reduced basal and $\mathrm{H}_{2} \mathrm{O}_{2}$-induced ROS levels in the immortalized nontumorigenic MCF10A human breast epithelial cell line. All these results suggest that HTyr, inhibiting ROS production, can prevent oxidative DNA damage in normal and non-transformed cells in vitro, thereby preventing the initiation of a chain of reactions that transforms normal into cancer cells Fig. (3). This hypothesis is supported by an intervention study-showing that the supplementation of postmenopausal women with high phenol extra-VOO caused decreased oxidative damage to lymphocyte DNA [81].

Beyond these data obtained in non-transformed cells, evidence exists that HTyr can directly prevent oxidative DNA damage also in transformed cells in vitro. In a recent study performed in the human skin keratinocyte $\mathrm{HaCaT}$ cell line exposed to UVB, Guo et al. [82] reported that HTyr significantly decreased intracellular ROS formation and 8-hydroxydeoxyguanosine levels, reducing DNA strand breaks and p53 expression. These results strongly suggest that HTyr has a significantly protective effect against UVB-induced oxidative DNA damage. Moreover, it has been shown that HTyr, at potential physiological concentrations $(1-100 \mu \mathrm{M})$, protects other different cancer cell types, such as those derived from gut [83], blood [84], prostate [57], and breast [80], against oxidative damage induced by $\mathrm{H}_{2} \mathrm{O}_{2}$. This means, as discussed above, that HTyr might also protect tumor cells from the cytotoxic/proapoptotic action of some chemotherapeutic agents.

\subsubsection{Indirect Antioxidant Activity of HTyr and Cancer}

Recent studies suggest that the anti-tumor effects mediated by HTyr are also derived from its indirect antioxidant activity, consisting in the regulation of enzymes and signaling molecules implicated in oxidation. In fact, an important aspect of the biochemistry of phenolic antioxidants is their ability to form a variety of highly interesting arylating oxidation products. In particular, Cornwell et al. [53] showed that HTyr, during its redox cycling, is converted to hydrophilic catechol quinone (hydroxytyrosol quinone, HTyrQ) electrophile. Thus, the hydrophilicity of HTyrQ allows it to react with available thiol nucleophilic groups (Michael addition reaction) present in enzymes and signaling molecules within the hydrophilic cell environment $[85,53]$.

It is of great interest that, HTyr $(100 \mu \mathrm{M})$ activates the nuclear factor-E2-related factor-2/antioxidant responsive element (Nrf2/ ARE) pathway in vitro, resulting in the increased transcription of both antioxidant enzymes (e.g. $\mathrm{Cu} / \mathrm{ZnSOD}, \mathrm{MnSOD}$, peroxiredoxin 3 and 5, thioredoxin-2) and phase II detoxifying enzymes (e.g. GSH S-transferase, NAD(P)H:quinone oxidoreductase 1 or GSH reductase) [86]. It is noteworthy, that the enhancement of phase II enzymes is a highly effective strategy for protection towards oxidant toxicity and carcinogenesis. Under basal conditions, Nrf2 is predominately bound into the cytoplasm to the Keap-1 protein, which is anchored to the actin cytoskeleton. When some inducers disrupt the Keap1-Nrf2 complex, Nrf2 is activated, migrates to the nucleus, heterodimerizes with a small MAF protein and binds to ARE in the upstream promoter region of many antioxidant genes. The activation of Nfr2 by HTyr might occur through the Michael addition reaction between HTyrQ and the cysteine thiol group in Keap-1, leading to Keap-1 dissociation from Nrf2 [85]. Moreover, by the activation of the Nfr2 and JNK-p62/SQSTM1 pathways, HTyr can induce the synthesis of GSH widely involved in tumorigenesis [87] Fig. (4). This hypothesis is supported by a very recent study in vivo, showing that a diet rich in olive oil phenols reduced oxidative stress in the heart of senescence-accelerated mouse-prone 8 mice by the induction of Nrf2-dependent gene expression [88].

In conclusion, many studies focused on the toxicity and carcinogenicity induced by ROS generated by redox-active metals, such as iron. In this context, it is important to underlie the indirect antioxidant activity of HTyr mediated through its strong iron chelating capability, leading to the decrease of iron-derived ROS and of oxidative stress generation [60].

\section{PROLIFERATION AND CANCER}

Physiological conditions, crucial mechanisms for maintaining tissue homeostasis are represented by the strict control of both cell proliferation and apoptosis under normal conditons. Shifting the balance from a state of equilibrium towards an increased proliferation can lead to the appearance of a neoplastic cell population. In fact, as above-mentioned, cancer hallmarks include insensitivity to growth-inhibitory signals, sustained growth-stimulatory signaling and evasion of apoptosis [52].

Concerning the control of cell proliferation by growthinhibitory signals, two main mechanisms were proposed by Hanahan and Weinberg [52]. The first mechanism is the prevention of normal cells to advance through the cell cycle G1 phase, maintaining cells in a quiescent (G0) state. An example of such an antigrowth signal is the soluble signaling factor transforming growth factor- $\beta$ (TGF $\beta$ ), which blocks progression through the G1 phase of the cell cycle via the suppression of c-Myc and the activation of cyclin-dependent kinase (Cdk) inhibitors $\mathrm{p} 15^{\mathrm{Ink} 4 \mathrm{~B}}$ and $\mathrm{p} 21^{\mathrm{Cip} 1}$ [89]. Often, cancer cells acquire the inability to respond to inhibitory factors as a result of inactivating mutations; or downregulation of both the downstream signaling effectors and the receptors themselves [89]. The second mechanism involves the implementation of 


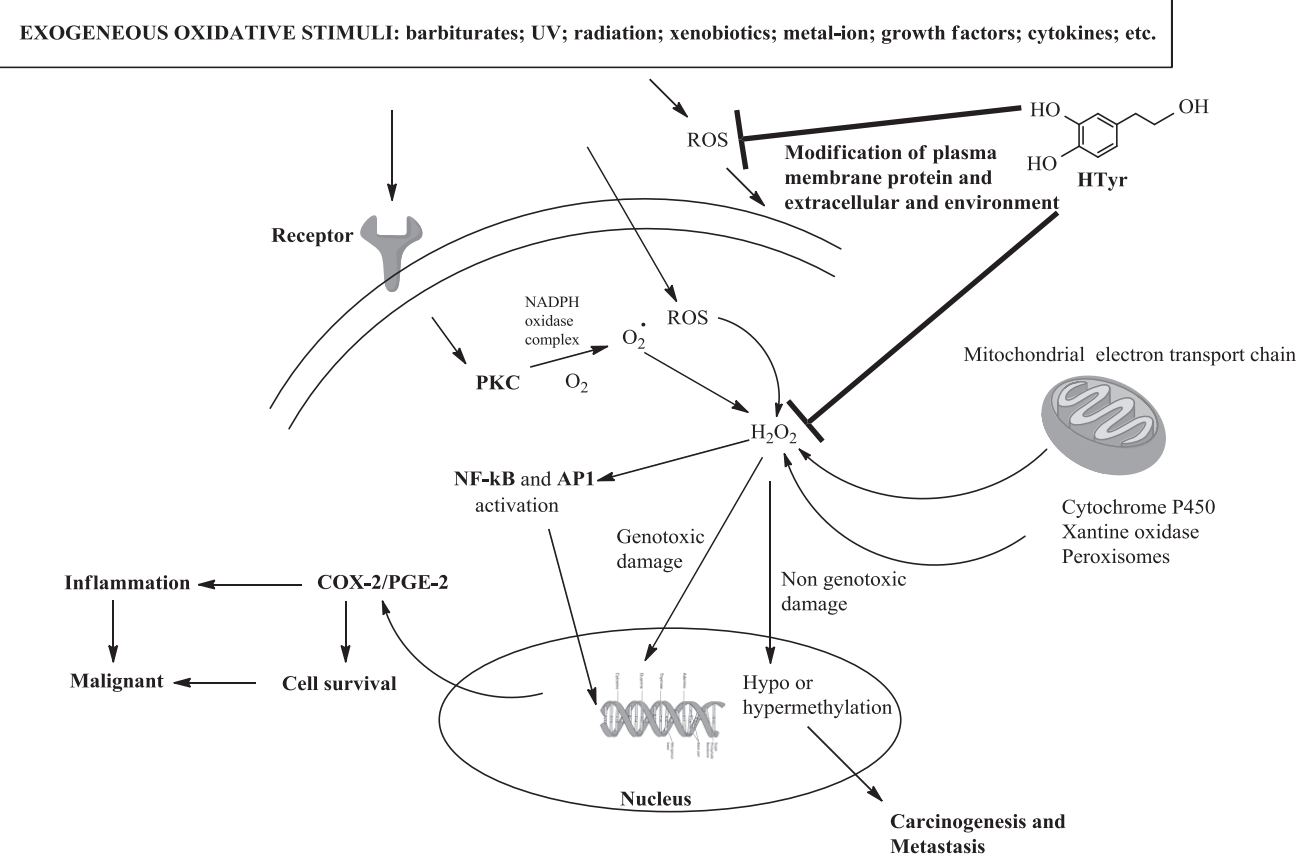

Fig. (3). Direct antioxidant activity of HTyr and cancer.

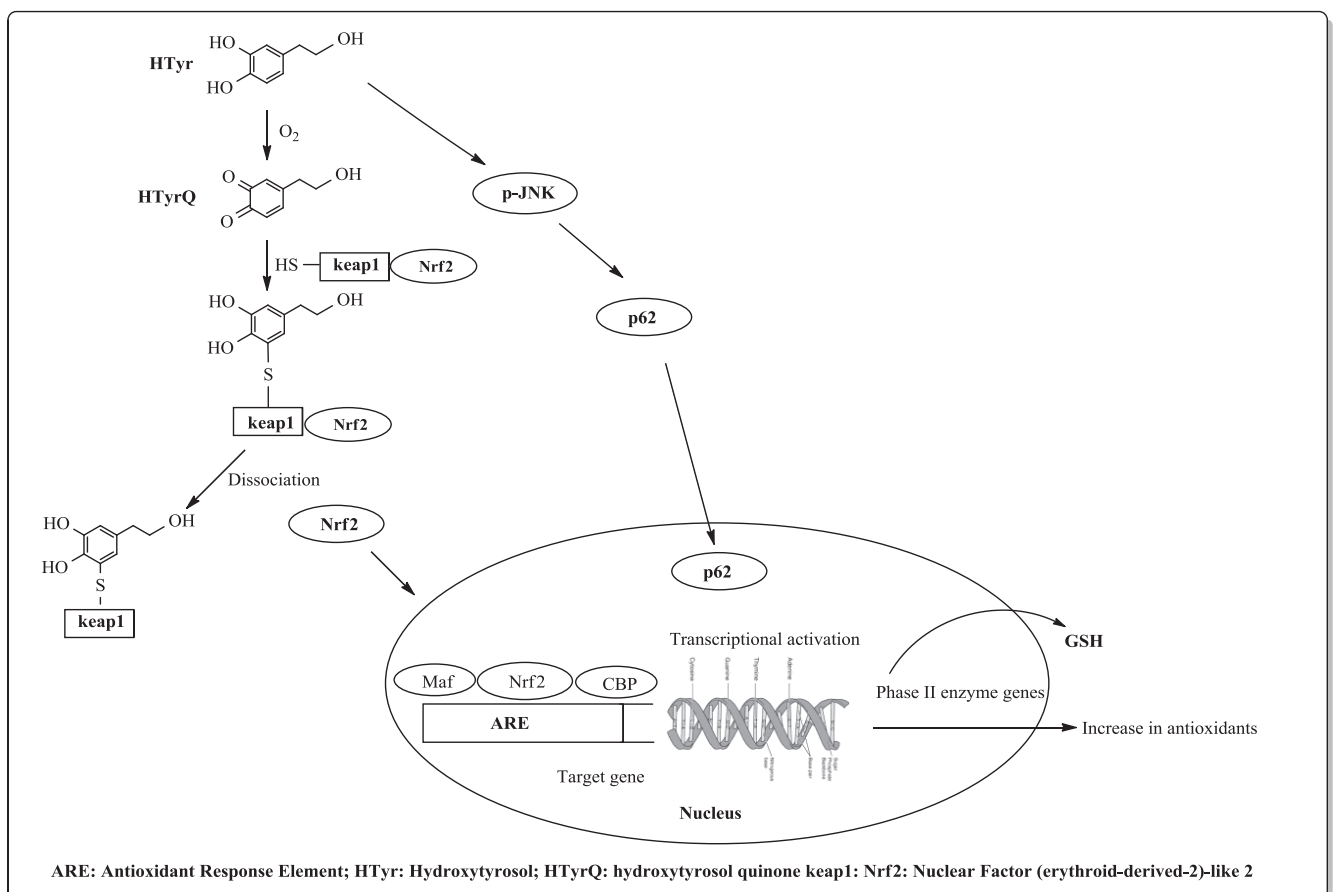

Fig. (4). Indirect antioxidant activity of HTyr and cancer.

differentiation programs, which induce an irreversible post-mitotic or terminally differentiated state. In certain cancer cells, the normal differentiation program is blocked and cells are maintained in a proliferative progenitor-like state.

Concerning the control of cell proliferation by growthstimulatory signaling, two major signaling pathways, such as the Ras-MAPK/extracellular signal-regulated protein kinase (ERK) (Ras-MAPK/ERK) [90] and the PI3K/Akt [91] cascades, are frequently involved in many human cancers. Deregulation of these pathways with promotion of self-sufficient cancer cell growth can occur by a variety of mechanisms, including mutations to both up- stream and downstream components. Moreover, in the absence of MAPK-and PI3K-signaling-activating mutations, alternative mecha nisms may arise activating these pathways and conferring tumor cell growth autonomy. For example, $\mathrm{COX}$-2-derived prostaglandinE2 (PGE2) (see 6. Inflammation and cancer) is able to signal via the Ras-MAPK/ERK and the PI3K/AKT-pathways to promote cell survival. Therefore, aberrant activation of the COX-2/PGE2 pathway could enhance Ras-MAPK and/or PI3K/AKT signaling activation, promoting tumorigenesis [92].

Finally, evasion of apoptosis, the process of programmed cell death used by organisms to control cell number, is another critical 
mechanism by which cancer cells result in excessive cell survival and increased proliferation [93]. The ability of tumor cells to acquire resistance to apoptosis can arise via a variety of mechanisms, the majority of which result in an impaired ability of the cell to engage the intrinsic cell death machinery, i.e. the mitochondrial apoptosis pathway. This pathway is governed by the ratio of proapoptotic and anti-apoptotic B-cell lymphoma 2 (Bcl-2) protein family members, which set a threshold for activation of the apoptotic caspase cascade upstream of the mitochondria [94]. Moreover, it should be emphasized that the deregulation of the Ras-MAPK/ ERK and the PI3K/AKT signaling pathways, beyond the induction of cell growth autonomy, can also cause the prevention of apoptosis via the intrinsic cell death machinery $[95,96]$.

\subsection{HTyr-Mediated Antiproliferative Activity and Cancer}

The anticancer activity of HTyr has been studied as the result of its capability to inhibit cell proliferation by suppressing cell cycle progression and growth, and/or promoting apoptosis in several cancer cell lines in vitro.

Della Ragione et al. [97] demonstrated that HTyr (50 and 100 $\mu \mathrm{M})$ reduced proliferation by arresting cell cycle and inducing apoptosis in the human promyelocytic leukemia HL60 cell line, as well as in resting and activated peripheral blood lymphocytes. They also indicated that HTyr-mediated apoptosis depended on the release of cytochrome c, which activated the effector caspase-3. Then, the same authors [98] proposed that one of the possible mechanisms by which HT triggered apoptosis by cytochrome c release, could be the activation of the c-jun NH2-terminal kinase (JNK) transduction pathway, which induces the phosphorylation of the anti-apoptotic protein Bcl-2, inactivating it, thus causing cancer cell apoptosis. Partially according to these results, Fabiani et al. $[98,100]$ showed that HTyr $(50$ and $100 \mu \mathrm{M})$ inhibited cell proliferation of HL-60 cells, by blocking the cell cycle in the G1 phase, promoting apoptosis and inducing cell differentiation. The authors proposed the following HTyr-mediated mechanisms: 1) inhibition of Cdk; 2) induction of CdK inhibitors; 3) blockage of messengers involved in cell proliferation. Then, the same authors [101] reported that HTyr $(100 \mu \mathrm{M})$ decreases the expression of Cdk6 and increased that of Cdk inhibitors p $21^{\text {WAF/Cip } 1}$ and p $27^{\text {Kip1 }}$ in the same cell type. They also proposed that HTyr-mediated apoptosis was due to both extracellular $\mathrm{H}_{2} \mathrm{O}_{2}$ production induced by the abovementioned HTyr-mediated pro-oxidant activity and the Michael addition reaction between HTyrQ and thiol groups in proteins, promoting endoplasmic reticulum (ER)-dependent stress with the consequent activation of pro-apoptotic signals [54, 102]. However, in contrast to Della Ragione et al. [95], no effect on apoptosis was observed on freshly isolated human lymphocytes and polymorphonuclear cells by Fabiani et al. [99]. This discrepancy could be due to the different apoptosis assays used by the two research groups.

Recently, Guichard et al. [103] demonstrated that high (100$400 \mu \mathrm{M})$ HTyr doses inhibited the proliferation of human colon carcinoma HT-29 cells by inducing both cell cycle arrest (at phases $\mathrm{S}$ and $\mathrm{G} 2 / \mathrm{M}$ ) and apoptosis through $\mathrm{JNK}, \mathrm{Bcl}-2$, cytochrome c release, and caspase-3 activation. The authors indicated that HTyr specifically activated serine/threonine phosphatase PP2A, either directly or indirectly, by scavenging ROS (which are known to inhibit PP2A) or by inducing ER-dependent stress (which enhance the PERK signaling pathway). PP2A is known to play a key role in triggering various signaling pathways leading to apoptosis. These results agree, at least in part, with those of Della Ragione et al. [98], reporting an inhibition of the pro-survival extracellular signalregulated kinase (Erk) 1/2- and PI3K/Akt- NF-kB pathways, probably by PP2A activation. Notarincola et al. [104] observed antiproliferative effects on HT-29 and on another human colon cancer SW620 cell line by potentially physiological (10-100 $\mu \mathrm{M}) \mathrm{HTyr}$ doses. Moreover, Corona et al. [105] showed that HTyr (50-100 $\mu \mathrm{M})$ exerted strong anti-proliferative effects against the Caco $2 \mathrm{hu}-$ man colon adenocarcinoma cell line, by accumulation of cells in the cell cycle G2 phase and inhibition of ERK1/2 phosphorylation. According to previous results [103, 105], we showed that high $(100-300 \mu \mathrm{M})$ HTyr concentrations induced dose-dependent antiproliferative effects on HT-29 cells, by the induction of cell cycle arrest in the G2/M phase [106].

Recently, Han et al. [107] studied the MCF-7 breast cancer cell line and found that HTyr $(324 \mu \mathrm{M})$ inhibited cell proliferation by both cell cycle arrest in G0/G1 phase and apoptosis. Moreover, in the same cancer cell model, Bouallagui et al. [108] reported that the G0/G1 phase cell cycle arrest was associated with both a downregulation of the expression of the peptidyl-prolyl cis-trans isomerase Pin-1, which in turn decreased cyclin D1 levels, and an upregulation of c-jun. In addition, Sirianni et al. [109] demonstrated that HTyr inhibited estradiol-induced MCF-7 cell proliferation by interfering with ERK1/2 activation.

The only in vivo study was performed by Granados-Principal et al. [110], showing that HTyr exerted anti-cancer effects in Sprague-Dawley rats with experimental mammary tumors by inhibiting cell growth, through the alteration of several genes associated with cell proliferation, apoptosis and the Wnt signaling pathway.

In contrast to these results showing the antiproliferative activity of HTyr, some authors have not detected any inhibition of cancer cell proliferation after HTyr treatment, also in the presence of HTyr-mediated reduction of oxidative cell damage [57, 80, 111]. These findings support the idea that, beyond the simple interference with radical processes, other mechanism(s) involving the specific interaction of HTyr with cellular target molecule(s) underlies HTyrmediated modulation of cell proliferation and apoptosis, and that further studies are necessary to elucidate the signaling events targeted by HTyr in cancer cell proliferation.

In conclusion, these data indicate that HTyr can mediate antiproliferative activity on cancer cells by potentially targeting specific oncogenic pathways. Moreover, most that is currently known comes from in vitro studies. In vivo investigations are needed to demonstrate the HTyr capability of inhibiting tumor cell proliferation.

\section{INFLAMMATION AND CANCER}

The immune system is considered as a "double-edged sword" in cancer, in that it protects the host destroying tumor cells (i.e. immuno-surveillance), and yet, paradoxically, it promotes and sustains cancer (the result of a process known as cancer immuno-editing) $[112,113]$. Hence, the effectiveness of immuno-surveillance and response to therapy depends on the balance between anti- and protumorigenic immunity [114].

Inflammation is an important part of the innate immune response and a salutary response to various insults. However, there is a growing body of evidence that inflammation is a critical component of protumorigenic immunity. Chronic inflammation associated with infections, autoimmunity, environmental and dietary exposures represents a promoter of tumor development, and several types of cancers (lung, colorectal, gastric, pancreatic, hepatocellular, cervical, ovarian, skin, bladder, gall bladder cancers) are associated with chronic inflammatory diseases $[115,116]$. In addition, inflammation can also follow tumor development. In fact, most, if not all, solid malignancies trigger an intrinsic inflammatory response that builds up a protumorigenic microenvironment, promoting cancer progression $[113,116]$. Therefore, inflammation can contribute to all the carcinogenic steps, such as cancer initiation (by innate immune cell-mediated oxidative cell damage; see 4. Oxidation and cancer), promotion (by inducing cell proliferation), and progression (by promoting neo-angiogenesis and metastasis). 
Moreover, inflammation can cause local immunosuppression, polarizing immunity towards a tumor-promoting phenotype [115, 116].

Recent research has highlighted an important role for monocytes/macrophages in the pro-tumor inflammatory reactions. Monocyte/macrophages are an exceptionally heterogeneous population of cells (e.g. M-1 and M-2 polarizing macrophages, dendritic cells-DC and myeloid-derived suppressor cells-MDSC), which function in distinct differentiation forms and adopt different activation states and functions in response to a changing microenvironment [117119]. Indeed, macrophages can be central orchestrators of chronic inflammatory diseases, predisposing to cancer initiation. Moreover, macrophages, together with $\mathrm{T}$ cells, are the most frequently found immune cells within the microenvironment of established tumors that are not epidemiologically related to chronic inflammation [120, 121], and high tumor-associated macrophages content generally correlates with poor prognosis [117]. Tumor-associated macrophages display several pro-tumorigenic functions, promoting tumor survival, tumor growth, neo-angiogenesis, invasion and metastasis, as well as, suppressing the anti-tumor immune response. Therefore, monocytes/macrophages can drive all the phases of carcinogenesis, from cancer initiation and immuno-editing to cancer progression and metastasization [118-121]. Once arrived in the inflamed tissue, macrophages produce protumorigenic inflammatory mediators and immunosuppressive factors, through the activation of their inflammatory signaling pathways [119]. The transcriptional factors NF-kB and HIF-1 have been identified as master regulators of macrophage transcriptional programs and, inducing the expression of genes encoding factors affecting malignant cells and tumor stroma, are central regulators of tumorigenesis [76, 122]. The protumorigenic mediators produced by macrophages include: a) growth factors (GF) (EGF, PDGF, FGF $\beta$, HGF), survival signals such as proinflammatory cytokines (tumor necrosis factor-TNF -, interleukin (IL)-1, IL-6), L-arginine derived polyamines, and PGE2; b) angiogenic factors such as vascular endothelial growth factor (VEGF), chemokines, cytokines (GM-CSF, TGF- and - $\beta$, TNF , IL-1, IL-6, IL-8), and PGE2; c) factors promoting invasion and metastasis such as chemokines, cytokines (TNF , IL-1) and enzymes (matrix metalloproteinases-MMP-9, urokinase-type plasminogen activator-uPA); d) immunosuppressive factors such as cytokines (e.g. IL-10, TGF$\beta)$, PGE2, indoleamine-2,3-dioxygenase (IDO), arginase, $\mathrm{O}_{2}{ }^{-}$, and peroxynitrite, which inhibit innate and adaptive anti-tumor immune responses [116, 120, 123].

\subsection{In Vitro HTyr-Mediated Anti-Inflammatory Activity and Cancer}

The anti-inflammatory activity of HTyr has been studied as the result of its capability of inhibiting the protumorigenic inflamma tory responses mediated by murine and human monocytes and macrophages in vitro.

Richard et al. [124] showed that the treatment of LPS-activated RAW264.7 murine macrophages with HTyr $(25 \mu \mathrm{M})$ reduced the production of several pro-inflammatory mediators, including cytokines (IL-12, IL-6, IL-1, TNF ), chemokines (CXCL10/IP-10, CCL2/MCP1, MIP-1 $\beta$ ) and enzymes (MMP-9, PGE2 synthase, and inducible nitric oxide synthase-iNOS-). Accordingly, Giner et al. [125] reported the inhibition of cytokine (IL-1 $\beta$, IL-6, and TNF ) production by LPS-stimulated peritoneal macrophages treated with HTyr $(100 \mu \mathrm{M})$. A similar anti-inflammatory activity was also shown in humans, where HTyr $(50-100 \mu \mathrm{M})$ remarkably inhibited, in a dose-dependent manner, TNF production and secretion by LPS-stimulated THP-1 monocytes [126]. Altogether, these results show that HTyr can inhibit macrophages/monocytes production of several inflammatory cytokines and enzymes that play a central role in tumorigenesis. In particular, TNF , acting on tumor and stromal cells, is a major mediator of cancer-related inflammation [127]. In fact, TNF can induce genetic changes and NF-kB activation in tumor cells, upregulating anti-apoptotic and cell cycle gene expression, thereby ensuring cell survival and proliferation. In addition, TNF , by NF-kB activation, upregulates COX-2 expression in tumor cells, and promotes tumor angiogenesis and metastasis. Finally, TNF suppresses adaptive and innate immunity. Because of these several important tumorigenic actions, TNF is now considered a therapeutic target in cancer treatment, and TNF antagonists have been shown to exert therapeutic activity in Phase I and II clinical cancer trials. Therefore, in the light of these considerations, we might assume that HTyr, by inhibiting TNF induction by macrophages, might play a key anti-tumor inflammatory action.

Maiuri et al. [128] demonstrated that HTyr (100-200 $\mu \mathrm{M})$ down-regulated, in a dose-dependent manner, the synthesis of PGE2 in LPS-stimulated J774 murine macrophages. Accordingly, Richard et al. [124] showed that HTyr inhibited PGE2 production in LPS-stimulated RAW264.7 murine macrophages. Maiuri et al. [128] also reported that the PGE2 synthesis down-regulation paralleled the inhibition of COX-2 gene expression in activated J774 macrophages. According to these results, Zhang et al. [129] showed that HTyr (50-100 $\mu \mathrm{M})$ suppressed COX-2 expression in LPSstimulated THP-1 monocytes. Since COX-2 is the enzyme deputed to PGE2 generation from arachidonic acid, these data show that HTyr blocks COX-2 production by macrophages, thus inhibiting the synthesis of PGE2. The fact that HTyr inhibits the COX-2PGE2 pathway in macrophages is very important, since PGE2 exerts pleiotropic effects on tumors influencing several aspects of tumorigenesis [92]. In fact, PGE2 promotes proliferation/survival (see 5. Proliferation and cancer) and metastasis in tumor cells, orchestrates the process of neo-angiogenesis in several ways, and act as an immunosuppressive factor. Altogether these considerations suggest that HTyr, inhibiting the COX-2-PGE2 pathway in macrophages, might play a central role in the suppression of tumorigenesis.

Interestingly, most of the authors cited above [124-126, 128] also showed that the HTyr-mediated inhibitory production of protumorigenic inflammatory factors by activated macrophages arises from the prevention of the activation of some transcriptional factors, including NF-kB. Importantly, NF-KB in macrophages regulates the expression of a large variety of genes encoding for immunoregulatory mediators (e.g. inflammatory cytokines and COX-2) implicated in carcinogenesis [74, 92]. Moreover, NF-kB inhibition by HTyr has been observed at physiological HTyr concentrations [124-126, 128]. The mechanism by which HTyr prevents the activation of transcription factors is not completely clear. Although most studies suggest that the anti-inflammatory effects of HTyr are mostly attributable to its antioxidant properties, as already mentioned in this review (see 4. Oxidation and cancer; 5. Proliferation and cancer), HTyr can also directly target specific biochemical and signaling oncogenic pathways $[47-49,53]$. One mechanism proposed for this activity involves HTyrQ from HTyr metabolism, which reacts with available thiol nucleophilic groups (Michael addition reaction) present in signaling molecules within the hydrophilic cell environment [53]. The fact that NF-kB contains a critical cysteine residue for its DNA binding capability, that can be inhibited by specific arylating agents, makes NF-kB a plausible and interest target. The capability of HTyr of bringing about arylating adducts in the residues of NF-kB cysteine, hampers the bonding of this transcription factor with DNA, thus inhibiting its activity [53] Fig. (5). It should be noted that, since several recent studies have been devoted to the development of new molecules that are inhibitors of the enzymatic activity of either iNOS or COX-2, the prevention by HTyr of the expression of the gene coding for these enzymes, through NF-kB inhibition, might represent an alternative molecular approach.

In conclusion, these data report that HTyr may act as a potent anti-inflammatory agent in vitro, by inhibiting pro-tumorigenic 


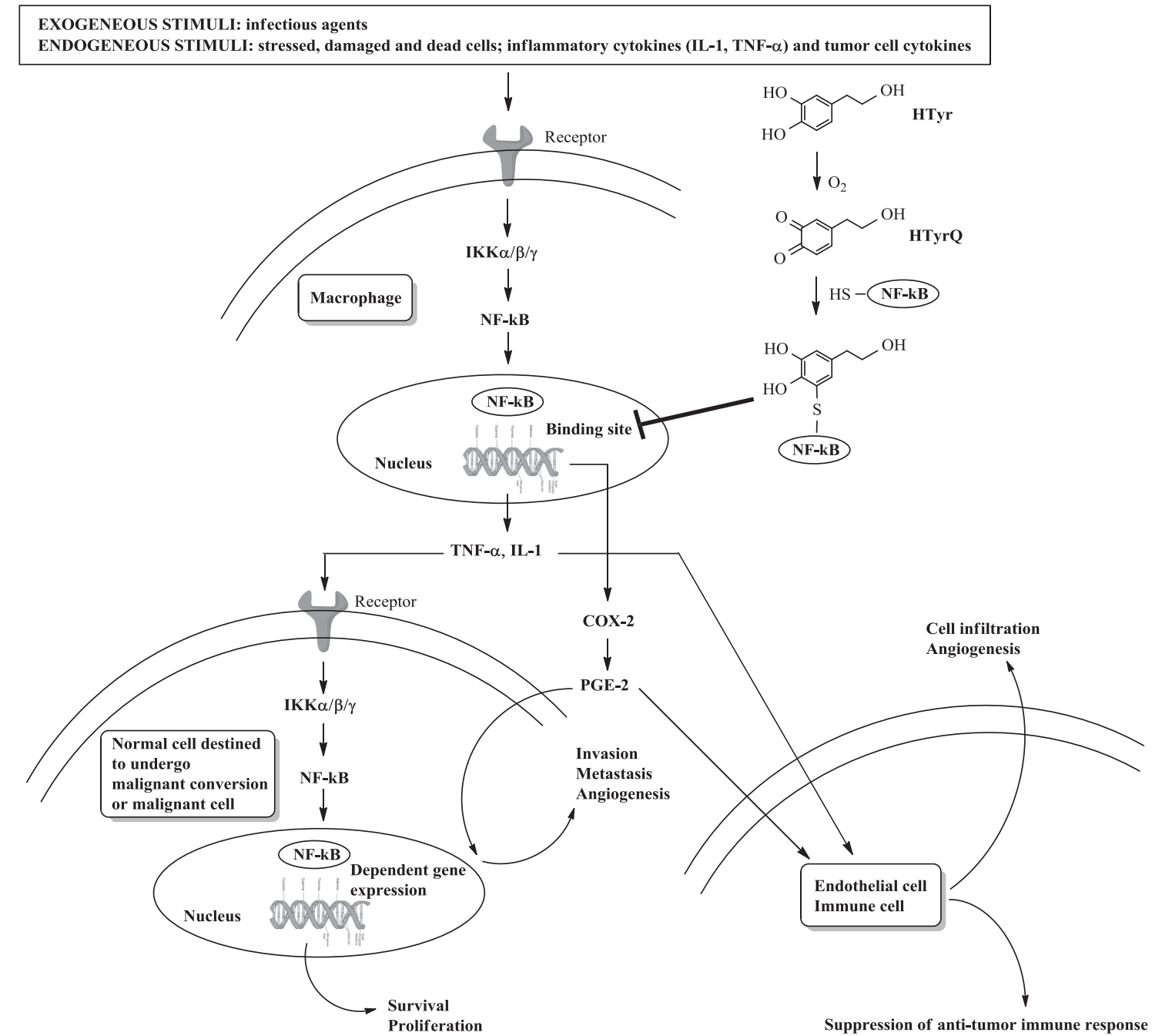

Fig. (5). Anti-inflammatory activity of HTyr and cancer.

inflammatory responses mediated by the activation of monocytes/macrophage. In particular, the inhibition of the NF-kB signaling pathways may play a central role in HTyr-mediated antiinflammatory activity.

\subsection{In Vivo HTyr-Mediated Anti-Inflammatory Activity and Cancer}

The in vivo anti-inflammatory effect of HTyr has been studied in different experimental animal models of inflammation. Bitler et al. [11] found that olive vegetation water highly enriched in HTyr (125 mg/mouse; $500 \mathrm{mg} / \mathrm{kg}$ ) reduced serum TNF levels by $95 \%$ in LPS-treated mice. Gong et al. [130] studied rats with acute inflammation induced by intravenous injection of carrageenan at $2 \%$ $(\mathrm{w} / \mathrm{v})$. The rodents received different dosages $(100,250$, and 500 $\mathrm{mg} / \mathrm{kg}$ of body weight) by gavage of a preparation in which the main ingredients were HTyr (22\%), polyphenol (4\%), saccharide $(67 \%)$, lipid (2\%), ignition residue $(4 \%)$, and moisture $(1 \%)$. This preparation, called HT-20, significantly inhibited the acute inflammation and lowered tissue IL-1 $\beta$ and TNF levels. More recently, Sánchez-Fidalgo et al. [131] reported that HTyr -enriched extraVOO attenuated chronic dextran sulfate sodium (DSS)-induced colitis in mice and decreased COX-2, iNOS via downregulation of p38MAPK. Accordingly, Giner et al. [125] found that oleuropein ameliorates acute DSS-colitis in mice while reducing TNF , IL-1 $\beta$ and IL- 6 production, iNOS, COX-2 and MMP-9 expression, and $\mathrm{NF}-\mathrm{kB}$ activation in colon tissue.
In conclusion, animal experiments support in vivo most of the evidence obtained in vitro, in that ingested HTyr exerts antiinflammatory activity, and this activity is very likely mediated by inhibiting macrophage production of protumorigenic inflammatory mediators, principally through the inhibition of NF-kB activation. However, it should be emphasized, that most of the experiments have been performed with mixture of olive phenols, in which HTyr was the most active ingredient but not the exclusive one. Synergy with other olive phenols cannot, at present, be excluded.

\section{CONCLUSIONS}

Epidemiological studies have shown an association between diets rich in olive oil phenols and lower cancer mortality. Current knowledge indicates HTyr as one of the major active phenolic components in olive oil, potentially capable of counteracting cancer hallmarks. In the last few years, several synthetic procedures have been optimized to obtain pure HTyr, so that the investigation of its biological activities could readily occur. The studies reported in this review indicate HTyr as a powerful antioxidant, as well as antiproliferative and anti-inflammatory agent, suggesting promising cancer chemopreventive and chemotherapeutic properties of HTyr. Efforts have been made nowadays to elucidate cellular and molecular targets of HTyr, and, notably, HTyr results as a potential multifunctional compound, capable of targeting multiple signaling oncogenic and inflammatory pathways. However, further studies in this direc- 
tion are still needed to clarify these activities. Moreover, as discussed here, most of the current knowledge comes from studies performed in vitro. Although these investigations largely contributes to a better understanding of the potential biological activities of HTyr, evidence obtained in vitro do not necessarily correspond to those found in vivo, especially when the concentrations of HTyr used in some experiments seems higher than those potentially achievable in vivo. Hence, preclinical research is needed to confirm HTyr-mediated anti-cancer activities and effectively utilize this compound in cancer prevention and treatment.

\section{CONFLICT OF INTEREST}

The author(s) confirm that this article content has no conflicts of interest.

\section{ACKNOWLEDGEMENTS}

The authors thank the Ministero dell'Istruzione, dell'Università e della Ricerca (MIUR) and the Università degli Studi della Tuscia (Viterbo, Italy) for their financial support.

\section{REFERENCES}

[1] Stoll, A.; Renz, J.; Brack, A. Antibacterial materials. VI. Isolation and constitution of echinacoside, a glycoside from the roots of Echinacea angustifolia D.C. Helv. Chim. Acta, 1950, 33, 1877-1893.

[2] Panizzi, L.; Scarpati, M.L.; Oriente, G. Chemical structure of oleuropein, bitter glucoside of olive with hypotensive activity. Gazz. Chim. Ital., 1966, 90, 1449-1485.

[3] (a) Ragazzi, E.; Veronesi, G. Ricerche sui costituenti idrosolubili delle olive I. Zuccheri e fenoli. Ann. Chim., 1967, 57, 1476-1486. (b) Montedoro, G.; Servili, M.; Baldioli, M.; Miniati, E. Simple and hydrolizable phenolic compounds in virgin olive oil. 1. Their extraction, separation and quantitative and semiquantitative evaluation by HPLC. J. Agric. Food Chem., 1992, 40, 15711576. (c) Montedoro, G.; Servili, M.; Baldioli, M.; Miniati, E. Simple and hydrolizable phenolic compounds in virgin olive oil. 2. Initial characterization of the hydrolizable fraction. J. Agric. Food Chem., 1992, 40, 1577-1580. (d) Montedoro, G.; Servili, M.; Baldioli, M.; Selvaggini, R.; Miniati, E.; Macchioni, A. Simple and hydrolizable phenolic compounds in virgin olive oil. 3. Spectroscopic characterization of the secoiridoids derivatives. J. Agric. Food Chem., 1993, 41, 2228-2234. (e) Ryan, D.; Antolovich, M.; Prenzler, P.; Robards, K.; Lavee, S. Biotransformations of phenolic compounds in Olea europea L. Scientia Horticulturae, 2002, 92, 147-176. (f) Visioli, F.; Galli, C. Olives and their production waste products as source of bioactive compounds. Curr. Top. Nutr. Res., 2003, 1, 85-88. (g) Bendini, A.; Cerretani, L.; Carrasco-Pancorbo, A.; Gomez-Caravaca, A.M.; Segura-Carretero, A.; Fernandez-Gutierrez, A.; Lercker, G. Phenolic molecules in virgin olive oils: a survey of their sensory properties, health effects, antioxidant activity and analytical methods. An overview of the last decade. Molecules, 2007, 12, 1679-1719.

[4] (a) Bonanome, A.; Pagnan, A.; Biffanti, S.; Opportuno, A.; Sorgato, F.; Dorella, M.; Maiorino, M.; Ursini, F. Effect of dietary monounsaturated and polyunsaturated fatty acids on the susceptibility of plasma low density lipoproteins to oxidative modification. Arterioscler. Thrombosis, 1986, 12, 529533. (b) Grignaffini, P.; Roma, P.; Galli, C.; Catapano, A. L. Protection of low-density lipoprotein from oxidation of 3,4-dihydroxyphenylethanol. Lancet, 1994, 343, 1296-1297. (c) Salami, M.; Galli, C.; De Angelis, L.; Visioli, F. Pharmacol. Res. 1995, 31, 275-279; Carluccio, M.A. (d) Visioli, F.; Galli, C. Natural antioxidants and prevention of coronary heart disease: the potential role of olive oil and its minor constituents. Nutr. Metabol. Cardiovasc. Dis. 1995, 5, 306-314. (e) Petroni, A.; Balsevich, M.; Salami, M.; Papini, N.; Montedoro, G.F.; Galli, C. Inhibition of platelet aggregation and eicosanoid production by phenolic components of olive oil. Thromb. Res. 1995, 78, 151160. (f) Hashimoto, T.; Ibi, M.; Matsuno, K.; Nakashima, S.; Tanigawa, T.; Yoshikawa, T.; Yabe-Nishimura, C. An endogenous metabolite of dopamine, 3,4-dihydroxyphenylethanol, acts as a unique cytoprotective agent against oxidative stress-induced injury. Free Radic. Bio. Med. 2004, 36, 555-564. (g) Nousis, L.; Doulias, P.; Aligiannis, N.; Bazios, D.; Agalias, A.; Galaris, D.; Mitakou, S. DNA protecting and genotoxic effects of olive oil related components in cells exposed to hydrogen peroxide. Free Radic. Res. 2005, 39, 787-795.

[5] (a) Visioli, F.; Galli, C. Oleuropein protects low density lipoprotein from oxidation. Life Sci., 1994, 55, 1965-1971. (b) Visioli, F.; Caruso, D.; Plasmati, D.; Patelli, E.; Mulinacci, R.; Romani, A.; Galli, C.; Galli, G. Hydroxytyrosol, as a component of olive mill waste water, is dose dependently absorbed and increases the antioxidant capacity of rat plasma. Free Radic. Res. 2001, 34, 301-305. (c) Salami, M.; Galli, C.; De Angelis, L.; Visioli, F. Formation of F2-isoprostanes in oxidized lowdensity lipoprotein: inhibitory effect of hydroxytyrosol. Pharmacol. Res., 1995, 31, 275-279.

[6] Visioli, F.; Galli, C. The effect of minor constituents of olive oil on cardiovascular disease: new findings. Nutr. Rew., 1998, 56, 142-147.

[7] (a) Fabiani, R.; De Bartolomeo, A.; Rosignoli, P.; Servili, M.; Montedoro, G.F.; Morozzi, G. Cancer chemoprevention by hydroxytyrosol isolated from virgin olive oil through G1 cell cycle arrest and apoptosis. Eur. J. Cancer Prev., 2002, 11, 351-358. (b) Fabiani, R.; De Bartolomeo, A.; Rosignoli, P.; Servili, M.; Selvaggini, R.; Montedoro, G.F.; Di Saverio, C.; Morozzi, G. Virgin olive oil phenols inhibit proliferation of human promyelocytic leukemia cells (HL60) by inducing apoptosis and differentiation. J. Nutr., 2006, 136, 614-619. (c) Fabiani, R.; Rosignoli, P.; De Bartolomeo, A.; Fuccelli, R.; Morozzi, G. Inhibition of cell cycle progression by hydroxytyrosol is associated with upregulation of cyclin-dependent protein kinase inhibitors p21 WAF1/Cip1 and p27Kip1 and with induction of differentiation in HL60 cells. J. Nutr., 2008, 138, 42-48.

isioli, F.; Bellomo, G.; Galli, C. Free radical scavenging properties of olive oil polyphenols. Biochem. Biophys. Res. Commun., 1998, 247, 60-64. (a) Manna, C.; Galletti, P.; Cucciolla, V.; Montedoro, G.; Zappia, V. Olive oil hydroxytyrosol protects human erythrocytes against oxidative damages. $J$. Nutr. Biochem., 1999, 10, 159-165. (b) Aruona, O.I.; Deiana, M.; Jenner, A.; Halliwell, B.; Harpakash, K.; Banni, S.; Corongiu, F.F.; Dessi, M.A.; Aeschbach, R. Effect of hydroxytyrosol found in extra virgin olive oil on oxidative DNA damage and on low-density lipoprotein oxidation. J. Agric. Food Chem., 1998, 46, 5181-5187.

[10] Visioli, F.; Galli, C.; Plasmati, E.; Viappiani, S.; Hernandez, A. Colombo, C.; Sala, A. Olive phenol hydroxytyrosol prevents passive smoking-induced oxidative stress. Circulation, 2000, 102, 2169-2171.

[11] Bitler, C.; Viale, T. M.; Damai, B.; Crea, R. Hydrolyzed olive vegetation water in mice has anti-inflammatory activity. J. Nutr., 2005, 135, 1475-1479. (a) Bisignano, G.; Tomaino, A.; Lo Cascio, R.; Crisafi, G.; Uccella, N.; Saija, A. On the in vitro antimicrobial activity of oleuropein and hydroxytyrosol. J. Pharm. Pharmacol., 1999, 51, 971-974. (b) Furneri, P. M.; Piperno, A.; Saija, A.; Bisignano, G. Antimycoplasmal activity of hydroxytyrosol. Antimicrob. Agents Chemother., 2004, 48, 4892-4894.

[13] Roig, A.; Cayuela, M. L.; Sanchez-Monedero, M. A. An overview on olive mill wastes and their valorisation methods. Waste Management, 2006, 26, 960-969.

[14] (a) Capasso, R.; Cristinzio, G.; Evidente, A.; Scognamiglio, F. Isolation, spectroscopy and selective phytotoxic effects of polyphenols from vegetable waste waters. Phytochemistry, 1992, 12, 4125-4128. (b) Della Greca, M.; Monaco, P.; Pinto, G.; Pollio, A.; Previtera, L.; Temussi, F. Phytotoxicity of low-molecular-weight phenols from olive mill waste waters. Bull. Environ. Contam. Toxicol. 2001, 67, 352-359. (c) Fiorentino, A.; Gentili, A.; Isidori, A.; Monaco, P.; Nardelli, A.; Parrella, A.; Temussi, F. Environmental effects caused by olive oil mill wastewaters: toxicity comparison of low-molecularweight phenol components. J. Agric. Food Chem., 2003, 51, 1005-1009.

[15] Rodis, P.S.; Karathanos, V.T.; Mantzavinou, A. Partitioning of olive oil antioxidants between oil and water phases. J. Agric. Food Chem., 2002, 50, 596-601.

[16] Sabatini, N. Recent patents in olive oil industry: new technologies for the recovery of phenols compounds from olive oil, olive oil industrial byproducts and waste waters. Recent Pat. Food, Nutr. Agric., 2010, 2, 154-159.

[17] (a) Crea, R. Method of obtaining a hydroxytyrosol-rich composition from vegetation water. US Patent 6,416,808. (b) Fernadez-Bolanos, G.J.; Guillen, B.R.; Rodriguez, A.R.; Rodriguez, G.G.; Heredia, M.A.; Jimenez, A.A. Method for obtaining purified hydroxytyrosol from products and by-products derived from the olive tree. Patent WO02064537. (c) Villanova, L.; Villanova, L.; Fasiello, G.; Merendino, A. Process for the recovery of tyrosol and hydroxytyrosol from oil mill waste-waters and catalytic oxidation method in order to convert tyrosol into hydroxytyrosol. US Patent 2006/0070953. (d) Pizzichini, M.; Russo, C. Process for recovering the components of olive mill waste water with membrane technologies. Int. Patent WO2005123603. (e) Pizzichini, D.; Russo, C.; Vitagliano, M.; Pizzichini, M.; Romani, A.; Ieri, F.; Pinelli, P.; Vignolini, P. Process for producing concentrated and refined actives from tissues and byproducts of Olea europea with membrane technologies. EP Patent 2,338,500A1.

[18] Campo, M.; Pinelli, P.; Romani, A. HPLC/DAD/MS characterization and antioxidant activity of sweet chestnut (Castanea sativa $\mathrm{M}$.) fractions. XXVI International Conference on Polyphenols, Florence, Italy, 22-25 July 2012; Vol.1, p.135-136.

[19] Pizzichini, M.; Romani, A.; Pizzichini, D.; Russo, C.; Pinelli, P. Process for producing refined nutraceutic extracts from artichoke waste and from other plants of the Cynara genus. PCT/IT2008/000135.

[20] Schöpf C.; Gottmann, G.; Meisel, E.-M. Uber b-(3,4-dioxyphenyl)athylalkohol. Liebigs Ann. Chem., 1949, 563, 86-93.

[21] Khafagy, E.Z.; Lambooy J.P. Preparation of substituted phenethyl alcohols 
and a study of their bacteriostatic action in Escherichia coli B. J. Med. Chem., 1966, 9, 936-940.

[22] Baraldi, P.G.; Simoni, D.; Manfredini, S.; Menziani, E. Preparation of 3,4dihydroxy-1-benzeneethanol: a reinvestigation. Liebigs Ann. Chem., 1983, 684-686.

[23] Capasso, R.; Evidente, A.; Avollo, S.; Solla, F.; A highly convenient synthesis of hydroxytyrosol and its recovery from agricultural waste waters. $J$. Agric. Food Chem., 1999, 47, 1745-1748.

[24] Tuck, K.L.; Tan, H.-W.; Hayball, P.J. Synthesis of tritium-labeled hydroxytyrosol, a phenolic compound found in olive oil. J. Agric. Food Chem., 2000, 48, 4087-4090.

[25] Bianco, A.; Passacantilli, P.; Righi, G. Improved procedure for the reduction of esters to alcohols by sodium borohydride. Synth. Comm., 1988, 18, 17651771 .

[26] Bai, C.; Yan, X.; Takenaka, M.; Sekiya, K.; Nagata, T. Determination of synthetic hydroxytyrosol in rat plasma by GC-MS. J. Agric. Food Chem., 1998, 46, 3998-4001.

[27] Espin, J.C.; Soler-Rivas, C.; Cantos, E.; Tomas-Barberan, F.; Wichers, H.J. Synthesis of the antioxidant hydroxytyrosol using tyrosinase as biocatalyst. J. Agric. Food Chem., 2001, 49, 1187-1193.

[28] Guazzaroni, M.; Crestini, C.; Saladino, R. Layer-by-Layer coated tyrosinase: An efficient and selective synthesis of catechols. Bioorg. Med. Chem., 2012, 20, 157-166.

[29] Allouche N.; Sayadi, S. Synthesis of hydroxytyrosol, 2-hydroxytyrosol, 2hydroxyphenylacetic acid and 3-hydroxyphenylacetic acid by differential conversion of tyrosol isomers using Serratia marcescens strain. J. Agric. Food Chem., 2005, 53, 6525-6530.

[30] Bouallagui, Z.; Sayadi, S. Production of high hydroxytyrosol via tyrosol conversion by Pseudomonas aeruginosa immobilized resting cells. J. Agric. Food Chem., 2006, 54, 9906-9911.

[31] Hartmann, C.; Meyer, V. Ueber jodobenzoësäure. Ber. Dtsch. Chem. Ges., 1893, 26, 1727-1732

[32] (a) Depernet, D.; François, B. WO 02/057210 A1, PCT/FR02/00189, US 2002/0107416; Chem. Abstr., 2002, 137, 109123. (b) Ozanne, O.; Pouységu, L.; Depernet, D.; François, B.; Quideau, S. A stabilized formulation of IBX (SIBX) for safe oxidation reactions including a new oxidative demethylation of phenolic methyl aryl ethers. Org. Lett., 2003, 5, 2903-2906. (c) Quideau, S.; Chénedé, A. Stabilized 2-Iodoxybenzoic Acid (SIBX). In: Encyclopedia of Reagents for Organic Synthesis (Online); John Wiley \& Sons Ltd., 2012, March 15, DOI: 10.1002/047084289X.rn01376.

[33] Sorg, G.; Mengel, A.; Jung, G.; Rademann, J. Oxidizing polymers: a polymer-supported, recyclable hypervalent iodine $(\mathrm{V})$ reagent for the efficient conversion of alcohols, carbonyl compounds, and unsaturated carbamates in solution. Angew. Chem. - Int. Edit., 2001, 40, 4395-4397.

[34] Bernini, R.; Fabrizi, G.; Pouységu, L.; Deffieux, D.; Quideau, S. Synthesis of biologically active catecholic compounds via ortho-selective oxygenation of phenolic compounds using hypervalent iodine(V) reagents. Curr. Org. Synth., 2012, 9, 650-669.

[35] De Lucia, M.; Panzella, L.; Pezzella, A.; Napolitano, A.; D’Ischia, M. Oxidative chemistry of the natural antioxidant hydroxytyrosol: hydrogen peroxidedependent hydroxylation and hydroquinone/o-quinone coupling pathways. Tetrahedron, 2006, 62, 1273-1278.

[36] Pouységu, L.; Sylla, T.; Garnier, T.; Rojas, L.B.; Charris, J.; Deffieux, D.; Quideau, S. Hypervalent iodine-mediated oxygenative phenol dearomatization reactions. Tetrahedron, 2010, 66, 5908-5917.

[37] Bernini, R.; Mincione, E.; Crisante, F.; Barontini, M.; Fabrizi, G. A novel use of the recyclable polymer-supported IBX: an efficient chemoselective and regioselective oxidation of phenolic compounds. The case of hydroxytyrosol derivatives. Tetrahedron Lett., 2009, 50, 1307-1310.

[38] (a) Bernini, R.; Mincione, E.; Barontini, M.; Crisante, F. Convenient synthesis of hydroxytyrosol and its lipophilic derivatives from tyrosol or homovanillyl alcohol. J. Agric. Food Chem., 2008, 56, 8897-8904. (b) Bernini, R.; Mincione, E.; Barontini, M.; Crisante, F. Procedimento per la preparazione di derivati dell'idrossitirosolo e di idrossitirosolo. IT Patent 0001381959, September 27, 2010. (c) Bernini, R.; Mincione, E.; Barontini, M.; Crisante, F. Procedimento per la preparazione di derivati dell'idrossitirosolo e di idrossitirosolo via demetilazione ossidativa. IT Patent 0001382586, December 22, 2010

[39] Bernini, R.; Cacchi, S.; Fabrizi, G.; Filisti, E. 2-Arylhydroxytyrosol derivatives via Suzuki-Miyaura cross-coupling. Org. Lett., 2008, 10, 3457-3460.

[40] Azabou, S.; Najjar, W.; Ghorbel, A.; Sayadi, S. Mild photochemical synthesis of the antioxidant hydroxytyrosol via conversion of tyrosol. J. Agric. Food Chem., 2007, 55, 4877-4882.

[41] Bovicelli, P.; Antonioletti, R.; Mancini, S.; Causio, S.; Borioni, G.; Ammendola, S.; Barontini, M. Expedient synthesis of hydroxytyrosol and its esters. Synth. Commun., 2007, 37, 4245-4252.

[42] Piersanti, G.; Retini, M.; Espartero, J.L.; Madrona, A.; Zappia, G. An efficient, economical synthesis of hydroxytyrosol and its protected forms via Baeyer-Villiger oxidation. Tetrahedron Lett., 2011, 52, 4938-4940.

[43] Verhe, R.; Papadoupolos, G.; Boskou, D. Preparation of hydroxytyrosol.
Bull. de Liaison - Groupe Polyphenols, 1992, 16, 237-244.

[44] Zhang, Z.-Li; Chen, J.; Xu, Q.; Rao, C.; Qiao, C. Efficient synthesis of hydroxytyrosol from 3,4-dihydroxybenzaldehyde. Synth. Comm., 2012, 42, 794-798.

[45] Gambacorta, A.; Tofani, D.; Bernini, R.; Migliorini, D. High-yielding preparation of a stable precursor of hydroxytyrosol by total synthesis and from the natural glycoside oleuropein. J. Agric. Food Chem., 2007, 55, 3386-3391.

[46] (a) Briante, R.; La Cara, F.; Tonziello, M. P.; Febbraio, F.; Nucci, R. Antioxidant activity of the main bioactive derivatives from oleuropein hydrolysis by hyperthermophilic $\beta$-glycosidase. J. Agric. Food Chem., 2001, 49, 3198 3203. (b) Briante, R.; La Cara, F.; Febbraio, F.; Patumi, M.; Nucci, R. Bioactive derivatives from oleuropein by a biotransformations on Olea europea leaf extracts. J. Biotechnol., 2002, 93, 109-119.

[47] Granados-Principal S ; Quiles, J.L.; Ramirez-Tortosa, C.L.; Sanchez-Rovira, P.; Ramirez-Tortosa, M.C. Hydroxytyrosol: from laboratory investigations to future clinical trials. Nutr. Rev., 2010, 68, 191-206.

[48] Visioli, F.; Bernardini, E. Extra virgin olive oil's polyphenols: biological activities. Curr. Pharm. Des., 2011, 17, 786-804.

[49] Kang, N.; Shin, S.H.; Lee, H.J. Lee, K.W. Polyphenols as small molecular inhibitors of signaling cascades in carcinogenesis. Pharmacol. Ther., 2011, 130, 310-324.

[50] Lee, K.W.; Lee, H.J. The roles of polyphenols in cancer chemoprevention Biofactors, 2006, 105-121.

[51] Hanahan, D.; Weinberg, R.A. The hallmarks of cancer. Cell., 2000, 100, 57 -

[52] Hanahan, D.; Weinberg, R.A. Hallmarks of cancer: the next generation. Cell., 2011, 144, 646-674.

[53] Cornwell, D.G.; Ma, J. Nutritional benefit of olive oil: the biological effects of hydroxytyrosol and its arylating quinone adducts. J. Agric. Food. Chem., 2008, 56, 8774-8786.

[54] Fabiani, R.; Sepporta, M.V.; Rosignoli, P.; De Bartolomeo, A.; Crescimanno, M.; Morozzi G. Anti-proliferative and pro-apoptotic activities of hydroxytyrosol on different tumour cells: the role of extracellular production of hydrogen peroxide. Eur. J. Nutr., 2012, 51, 455-464.

[55] Visioli, F.; Galli, C.; Grande, S.; Colonnelli, K.; Patelli, C.; Galli, G, Caruso, D. Hydroxytyrosol excretion differs between rats and humans and depends on the vehicle of administration. J. Nutr., 2003, 133, 1612-1615.

[56] González-Santiago, M,; Fonollá, J,; Lopez-Huertas, E. Human absorption of a supplement containing purified hydroxytyrosol, a natural antioxidant from olive oil, and evidence for its transient association with low-density lipoproteins. Pharmacol. Res., 2010, 61, 364-370.

[57] Quiles, J.L.; Farquharson, A.J.; Simpson, D.K.; Grant, I.; Wahle, K.W. Olive oil phenolics: effects on DNA oxidation and redox enzyme mRNA in prostate cells. Br. J. Nutr., 2002, 88, 225-234

[58] Rizzo, A.M.; Berselli, P.; Zava, S.; Montorfano, G.; Negroni, M.; Corsetto, P.; Berra, B. Endogenous antioxidants and radical scavengers. Adv. Exp. Med. Biol., 2010, 698, 52-67.

[59] Klaunig, J.E.; Wang, Z.; Pu, X.; Zhou, S. Oxidative stress and oxidative damage in chemical carcinogenesis. Toxicol. Appl. Pharmacol., 2011, 254, $86-99$.

[60] Valko, M.; Rhodes, C.J.; Monocol, J.; Izakovic, M.; Mazur, M. Free radicals, metals and antioxidants in oxidative stress-induced cancer. Chem. Biol. In teract., 2006, 160, 1-40.

[61] Palmer, H.J.; Paulson, K.E. Reactive oxygen species and antioxidants in signal transduction and gene expression. Nutr. Rev., 1997, 55, 353-361.

[62] Halliwell, B. Antioxidants in human health and disease. Ann. Rev. Nutr. 1996, 16, 33-50

[63] Grek, CL.; Tew, K.D. Redox metabolism and malignancy. Curr. Opin. Pharmacol., 2010, 10, 362-368.

[64] Nishikawa, M.; Hyoudou, K.; Kobayashi, Y.; Umeyama, Y.; Takakura, Y.; Hashiba, M. Inhibition of metastatic tumor growth by targeted delivery of antioxidant enzymes. J. Control. Release, 2005, 109, 101-107.

[65] Klauning, E.L.; Kamendulis, M. The role of oxidative stress in carcinogenesis. Annu. Rev. Pharmacol. Toxicol., 2004, 44, 239-267.

[66] Storz, P. Reactive oxygen species in tumor progression. Front. Biosci., 2005, 10, 1881-1896.

[67] Ziech, D.; Franco, R.; Pappa, A.; Panayiotidis. M.I. Reactive oxygen species (ROS) induced genetic and epigenetic alterations in human carcinogenesis. Mutat. Res, 2011, 711, 167-173.

[68] Shokolenko, I.; Venediktova, N.; Bochkareva, A.; Wilson, G. L.; Alexeyev M. F. Oxidative stress induces degradation of mitochondrial DNA. Nucleic Acids Res., 2009, 37, 2539-2548.

[69] Campos, A.C.E.; Molognoni, F.; Melo, F.H.M.; Galdier, L.C.; Carneiro, C.R.W.; D'Almeida, V.; Correa, M.; Jasiulionis, M. Oxidative stress modulate DNA methylation during melanocyte anchorage blockade associated with malignant transformation. Neoplasia, 2007, 9, 1111-1121.

[70] Donkena, K.V.; Young, C.Y.; Tindall, D.J. Oxidative stress and DNA methylation in prostate cancer. Obstet. Gynecol. Int., 2010, 2010, 1-14.

[71] Franco, R.; Schoneveld, O.; Georgakilas, A.; Panayiotidis, M. Oxidative stress, DNA methylation and carcinogenesis. Cancer Lett., 2008, 266, 6-11. 
[72] Lim, S.O.; Gu, J.M.; Kim, M.S.; Kim, H.S.; Park, Y.N.; Park, C.K.; Cho, J.W.; Park, Y.M.; Jung, G. Epigenetic changes induced by reactive oxygen species in hepatocellular carcinoma: methylation of the E-cadherin promoter. Gastroenterology, 2008, 135, 2128-2140.

[73] Thannickal, V.J.; Fanburg, B.L.; Reactive oxygen species in cell signaling. Am. J. Physiol. Lung Cell. Mol. Physiol., 2000, 279, L1005-L1028.

[74] Karin, M. Nuclear factor-kB in cancer development and progression. Nature, 2006, 44, 431-436.

[75] Bors, W.; Michel, C. Chemistry of the antioxidant effect of polyphenols. Ann. N. Y. Acad. Sci., 2002, 957, 57-69.

[76] Montero, A.J.; Jassem, J. Cellular redox pathways as a therapeutic target in the treatment of cancer. Drugs, 2011, 71, 1385-1396.

[77] O’Dowd, Y.; Driss, F.; Dang, P.M.; Elbim, C.; Gougerot-Pocidalo, M.A.; Pasquier, C.; El-Benna, J. Antioxidant effect of hydroxytyrosol, a polyphenol from olive oil: scavenging of hydrogen peroxide but not superoxide anion produced by human neutrophils. Biochem. Pharmacol., 2004, 68, 2003-2008. Manna, C.; Galletti, P.; Cucciola, V.; Montedoro, G.F.; Zappia, V. Olive oil hydroxytyrosol protects human erythrocytes against oxidative damages. $J$. Nutr. Biochem., 1999, 10, 159-165.

[79] Fabiani, R.; Rosignoli, P.; De Bartolomeo, A.; Fuccelli, R.; Servili, M.; Montedoro, G.F.; Morozzi, G. Oxidative DNA damage is prevented by extracts of olive oil, hydroxytyrosol and other olive phenolic compounds in human blood mononuclear cells and HL60 cells. J. Nutr. 2008, 138, 14111416

[80] Warleta, F.; Quesada, C.S.; Campos, M.; Allouche, Y.; Beltràn, G.; Gaforio, J.J. Hydroxytyrosol protect against oxidative DNA damage in human breast cells. Nutrients, 2011, 3, 839-857.

[81] Salvini, S.; Sera, F.; Caruso, D.; Giovannelli, L.; Visioli, F.; Saieva, C.; Masala, G.; Ceroti, M; Giovacchini, V.; Pitozzi, V.; Galli, C.; Romani, A.; Mulinacci, N.; Bortolomeazzi, R.; Dolara, P.; Palli, D. Daily consumption of a high phenol extra-virgin olive oil reduces oxidative DNA damage in postmenopausal women. Br. J. Nutr., 2006, 95, 742-751

[82] Guo, W.; An, Y.; Jiang, L.; Geng, C.; Zhong, L. The protective effects of hydroxytyrosol against UVB-induced DNA damage in HaCaT cells. Phytother. Res., 2010, 24, 352-359.

[83] Manna, C.; Galletti, P.; Cucciola, V.; Moltedo, O.; Leone, A.; Zappia, V. The protective effect of the olive oil polyphenol (3,4-dihydroxyphenyl)-ethanol counteracts reactive oxygen metabolite-induced cytotoxicity in Caco- 2 cells. J. Nutr., 1997, 127, 286-292.

[84] Nousis, L.; Doulias, P.T.; Aligiannis, N.; Bazios, D.; Agalias, A.; Galaris, D.; Mitakou, S. DNA protecting and genotoxic effects of olive oil related components in cells exposed to hydrogen peroxide. Free Radic. Res., 2005, 39, 787-795.

[85] Dinkova-Kostova, A.T.; Holtzclaw, W.D.; Cole, R.N.; Itoh, K.; Wakabayashi, N.; Katoh, Y.; Yamamoto, M.; Talalay, P. Direct evidence that sulfhydryl groups of Keap1 are the sensors regulating induction of phase 2 enzymes that protect against carcinogens and oxidants. Proc. Natl. Acad. Sci. USA, 2002, 99, 11908-11913.

[86] Zhu, L.; Liu, Z.; Feng, Z.; Hao, J.; Shen, W.; Li, X.; Sun, L.; Sharman, E.; Wang, Y.; Wertz, K.; Weber, P.; Shi, X.; Liu, J. Hydroxytyrosol protects against oxidative damage by simultaneous activation of mitochondrial biogenesis and phase II detoxifying enzyme systems in retinal pigment epithelial cells. J. Nutr. Biochem., 2010, 21, 1089-1098.

[87] Zou, X.; Feng, Z.; Li, Y.; Wang, Y.; Wertz, K.; Weber, P.; Fu, Y.; Liu, J. Stimulation of GSH synthesis to prevent oxidative stress-induced apoptosis by hydroxytyrosol in human retinal pigment epithelial cells: activation of Nrf2 and JNK-p62/SQSTM1 pathways. J. Nutr. Biochem., 2012, 23, 9941006

[88] Bayram, B.; Ozcelik, B.; Grimm, S.; Roeder, T.; Schrader, C.; Ernst, I.M.; Wagner, A.E.; Grune, T.; Frank, J.; Rimbach, G. A diet rich in olive oil phenolics reduces oxidative stress in the heart of SAMP8 mice by induction of Nrf2-dependent gene expression. Rejuvenation. Res., 2012, 15, 71-81.

[89] Massague, J. TGFbeta in cancer. Cell, 2008, 134, 215-230.

[90] Downward, J. Targeting RAS signalling pathways in cancer therapy. Nat. Rev. Cancer, 2003, 3, 11-22.

[91] Vivanco, I.; Sawyers, C.L. The phosphatidylinositol 3-Kinase AKT pathway in human cancer. Nat. Rev. Cancer, 2002, 2, 489-501.

[92] Greenhough, A.; Smartt, H.J.M.; Moore, A.E.; Roberts, H.R.; Williams, A.C., Paraskeva, C., Kaidi, A. The COX-2/PGE2 pathway: key roles in the hallmarks of cancer and adaptation to the microenvironment. Carcinogenesis, 2009, 30, 377-386.

[93] Green, D.R.; Evan, G.I. A matter of life and death. Cancer Cell, 2002, 1, 1930 .

[94] Danial, N.N.; Korsmeyer, S.J.; Cell death: critical control points. Cell, 2004, 116, 205-219

[95] Datta, S.R.; Dudek, H.; Tao, X.; Masters, S.; Fu, H.; Gotoh, Y.; Greenberg, M.E. Akt phosphorylation of BAD couples survival signals to the cellintrinsic death machinery. Cell., 1997, 91, 231-241.

[96] Bonni, A.; Brunet, A.; West, A.E.; Datta, S.R.; Takasu, M.A.; Greenberg, M.E. Cell survival promoted by the Ras-MAPK signaling pathway by tran- scription-dependent and -independent mechanisms. Science, 1999, 286, 1358-1362.

[97] Della Ragione, F.; Cucciolla, V.; Borriello, A.; Della Pietra V, Manna C, Galletti P, Zappia V. Pyrrolidine dithiocarbamate induces apoptosis by a cytochrome c-dependent mechanism. Biochem. Biophys. Res. Commun., 2000, 268, 942-946.

[98] Della Ragione, F.; Cucciolla, V.; Criniti, V.; Indaco, S.; Borriello, A.; Zappia, V. Antioxidants induce different phenotypes by a distinct modulation of signal transduction. FEBS Lett., 2002, 532, 289-294.

[99] Fabiani, R.; De Bartolomeo, A.; Rosignoli, P.; Servili, M.; Montedoro, G.F.; Morozzi, G. Cancer chemoprevention by hydroxytyrosol isolated from virgin olive oil through G1 cell cycle arrest and apoptosis. Eur. J. Cancer. Prev., 2002, 11, 351-358.

[100] Fabiani, R.; De Bartolomeo, A.; Rosignoli, P.; Servili, M.; Selvaggini, R Montedoro, G. F.; Di Saverio, C.; Morozzi, G. Virgin olive oil phenols inhibit proliferation of human promyelocytic leukemia cells (HL60) by inducing apoptosis and differentiation. J. Nutr., 2006, 136, 614-619.

[101] Fabiani, R.; Rosignoli, P.; De Bartolomeo, A.; Fuccelli, R.; Morozzi, G. Inhibition of cell cycle progression by hydroxytyrosol is associated with upregulation of cyclin-dependent protein kinase inhibitors p21(WAF1/Cip1) and $\mathrm{p} 27(\mathrm{Kip} 1)$ and with induction of differentiation in HL60 cells. J. Nutr., 2008,138, 42-48.

[102] Fabiani, R.; Fuccelli, R.; Pieravanti, F.; De Bartolomeo, A.; Morozzi, G. Production of hydrogen peroxide is responsible for the induction of apoptosis by hydroxytyrosol on HL60 cells. Mol. Nutr. Food. Res., 2009, 53, 887-896.

[103] Guichard, C.; Pedruzzi, E.; Fay, M.; Marie, J.C. Braut-Boucher, F.; Daniel, F.; Grodet, A.; Gougerot-Pocidalo, M.A.; Chastre, E.; Kotelevets, L.; Lizard, G.; Vandewalle, A.; Driss, F.; Ogier-Denis, E. Dihydroxyphenylethanol induces apoptosis by activating serine/threonine protein phosphatase PP2A and promotes the endoplasmic reticulum stress response in human colon carcinoma cells. Carcinogenesis, 2006, 27, 1812-1827.

[104] Notarincola, M.; Pisanti, S.; Tutino, V.; Bocale, D.; Rotelli M. T; Gentile A.; Memeo V.; Bifulco M.; Perri E.; Caruso M. G. Effects of olive oil polyphenols on fatty acid synthase gene expression and activity in human colorectal cancer cells. Genes. Nutr., 2011, 6, 63-69.

[105] Corona, G.; Deiana, M.; Incani, A.; Vauzour, D.; Dessì, M.A.; Spencer, J.P. HT inhibits proliferation of human colon adenocarcinoma cells through inhibition of ERK1/2 and cyclin D1. Mol. Nutr. Food Res., 2009, 53, 897-903.

[106] Bernini, R.; Crisante, F.; Merendino, N.; Molinari, R.; Soldatelli, M.C. Velotti, V. Synthesis of a novel ester of hydroxytyrosol and a-lipoic acid exhibiting an antiproliferative effect on human colon cancer HT-29 cells. Eur J. Med. Chem., 2011, 46, 439- 446 .

[107] Han, J.; Talorete, T.; Yamada, P.; Isoda, H. Anti-proliferative and apoptotic effects of oleuropein and hydroxytyrosol on human breast cancer MCF-7 cells. Cytotechnology, 2009, 59, 45-53.

[108] Bouallagui, Z.; Han, J.; Isoda, H.; Sayadi, S.; Hydroxytyrosol rich extract from olive leaves modulates cell cycle progression in MCF-7 human breast cancer cells. Food. Chem. Toxicol., 2011, 49, 179-184.

[109] Sirianni, R.; Chimento, A.; De Luca, A.; Casaburi, I.; Rizza, P.; Onofrio, A.; Iacopetta, D.; Puoci, F.; Andò, S.; Maggiolini, M.; Pezzi. V. Oleuropein and HT inhibit MCF-7 breast cancer cell proliferation interfering with ERK1/2 activation. Mol. Nutr. Food Res., 2009, 53, 536-545.

[110] Granados-Principal, S.; Quiles, J. L.; Ramirez-Tortosa, C.; CamachoCorencia, P.; Sanchez-Rovira, P.; Vera-Ramirez, L.; Ramirez-Tortosa, MC. Hydroxytyrosol inhibits growth and cell proliferation and promotes high expression of sfrp4 in rat mammary tumours. Mol. Nutr. Food Res., 2011, 55, 117-126.

[111] Menendez JA. Olive oil's bitter principle reverses acquired autoresistance to trastuzumab (HerceptinTM) in HER2-overexpressing breast cancer cells. BMC Cancer, 2007, 7, 80-99.

[112] Dunn, G.P.; Bruce, A.T.; Ikeda, H.; Old. L.J.; Schreiber, R.D. Cancer immunoediting: from immunosurveillance to tumor escape. Nat. Immunol., 2002 3, 991-998.

[113] Vesely, M.; Kershaw, M.H.; Schrieber, R.D.; Smyth, M.J. Natural innate and adaptive immunity to cancer. Annu. Rev. Immunol., 2011, 29, 235-271.

[114] Ostrand-Rosenberg, S. Immune surveillance: a balance between pro- and anti-tumor immunity. Curr. Opin. Genet. Dev., 2008, 18, 11-18.

[115] Coussens L. M.; Werb, Z. Inflammation and cancer. Nature, 2002, 420, 860867.

[116] Grivennikov, S. I.; Greten, F. R; Karin, M. Immunity, inflammation and cancer. Cell, 2010, 140, 833-899.

[117] Mantovani, A.; Sozzani, S.; Locati, M.; Allavena, P.; Sica, A. Macrophage polarization: tumor associated macrophages as a paradigm for polarized M2 mononuclear phagocytes. Trends Immunol., 2002, 23, 549-555.

[118] Pollard, J. W. Tumor-educated macrophages promote tumor progression and metastasis. Nat. Rev. Cancer, 2004, 4, 71-78.

[119] Murray, P.J.; Wynn, T.A. Protective and pathogenic functions of macrophage subsets. Nat. Rev. Cancer, 2011, 11, 723-737.

[120] Quian, B.Z.; Pollard, J.W. Macrophage diversity enhances tumor progression and metastasis. Cell, 2010, 141, 39-51. 
[121] Pagès, F.; Galon. J.; Dieu-Nosjean, M.C.; Tartour, E.; Sautès-Fridman, C.; Fridman, W.H. Immune infiltration in human tumors: a prognostic factor that should not be ignored. Oncogene, 2010, 29, 1093-1102.

[122] Mantovani, A.; Sica, A. Macrophages, innate immunity and cancer: balance, tolerance, and diversity. Curr. Opin. Immunol., 2010, 22, 231-237.

[123] Gabrilovich, D.I.; Nagaraj, S. Myeloid-derived suppressor cells as regulators of the immune system. Nat. Rev. Immunol., 2009, 9, 162-174.

[124] Richard, N.; Arnold, S.; Hoeller, U.; Kilpert, C.; Wertz, K.; Schwager, J. Hydroxytyrosol is the major anti-inflammatory compound in aqueous olive extracts and impairs cytokine and chemokine production in macrophages. Planta Med., 2011, 77, 1890-1897.

[125] Giner, E.; Andújar. I.; Recio, M.C.; Ríos, J.L; Cerdá-Nicolás, J.M.; Giner, R.M. Oleuropein ameliorates acute colitis in mice. J. Agric. Food. Chem., 2011, 59, 12882-12892.

[126] Zhang, X.; Cao, J.; Zhong, L. Hydroxytyrosol inhibits proinflammatory cytokines, iNOS, and COX-2 expression in human monocytic cells. Naunyn
Schmiedebergs Arch. Pharmacol., 2009, 379, 581-586.

[127] Balkwill, F. Tumor necrosis factor and cancer. Nat. Rev. Cancer, 2009, 9, 361-371.

[128] Maiuri, M.C.; De Stefano, D.; Di Meglio, P.; Irace, C.; Savarese, M.; Sacchi, R.; Cinelli, M.P.; Carnuccio, R. Hydroxytyrosol, a phenolic compound from virgin olive oil, prevents macrophage activation. Naunyn Schmiedebergs Arch. Pharmacol., 2005, 371, 457-465.

[129] Zhang, X.; Cao, J.; Jiang, L.; Zhong, L.; Suppressive effects of hydroxytyrosol on oxidative stress and nuclear factor kappa B activation in THP-1 cells. Biol. Pharm. Bull., 2009, 32, 578-582.

[130] Gong D, Geng C, Jiang L, Cao J, Yoshimura H, Zhong L.Effects of hydroxytyrosol-20 on carrageenan-induced acute inflammation and hyperalgesia in rats. Phytother. Res., 2009, 23, 646-650.

[131] Sánchez-Fidalgo, S.; Sánchez de Ibargüen, L.; Cárdeno, A.; Alarcón de Lastra C. Influence of extra virgin olive oil diet enriched with hydroxytyrosol in a chronic DSS colitis model. Eur. J. Nutr., 2012, 51, 497-506. 